Portland State University

PDXScholar

Winter 3-6-2019

\title{
Grappling with the African E-Waste Pandemic: Contributing Factors and Future Deterrence
}

Brittany Nicole Wideman

Portland State University

Follow this and additional works at: https://pdxscholar.library.pdx.edu/open_access_etds

Part of the Political Science Commons

Let us know how access to this document benefits you.

\section{Recommended Citation}

Wideman, Brittany Nicole, "Grappling with the African E-Waste Pandemic: Contributing Factors and Future Deterrence" (2019). Dissertations and Theses. Paper 4828.

https://doi.org/10.15760/etd.6704

This Thesis is brought to you for free and open access. It has been accepted for inclusion in Dissertations and Theses by an authorized administrator of PDXScholar. Please contact us if we can make this document more accessible: pdxscholar@pdx.edu. 
Grappling with the African E-Waste Pandemic:

Contributing Factors and Future Deterrence

by

Brittany Nicole Wideman

A thesis submitted in partial fulfillment of the requirements for the degree of

\author{
Master of Arts \\ in Political Science
}

\author{
Thesis Committee: \\ Joshua Eastin, Chair \\ David Kinsella \\ Birol Yesilada
}

Portland State University

2019 


\begin{abstract}
Electronic waste is the fastest growing waste stream worldwide. Illegal methods of transport, indifference in legislative response, and public ignorance of what to do in response, all influence e-waste proliferation. This dirty industry of e-waste is hazardous to human health and well-being as well as the environment. Since this dirty industry has ballooned over the last few decades, two major questions arise: What are the primary and secondary factors that influence the proliferation of e-waste dumping in developing countries; and what structures are emerging to combat the e-waste problem in developing countries in Africa? The following pages will investigate the e-waste problem in Africa; Egypt, Nigeria, and South Africa. I will show the role that small and medium industries play in managing the e-waste problem. Through a mass media search of key SMEs and organizations, I find that local enterprises are taking on an extended responsibility to find economic incentives in the e-waste industry and transform it from a vastly hazardous waste stream to a cooperative trade and flourishing industry. The results of these case studies illuminate how lax government regulation and involvement forces smaller businesses and organizations to emerge as the leaders in e-waste management.
\end{abstract}




\section{Dedication}

For my grandparents, Fletch and Shirley Wideman, without whom this project and the many milestones leading up to its completion would have been insurmountable and incomplete. May we all express the same unconditional compassion and endless wisdom.

From the depths of my being 


\section{Acknowledgements}

Foremost, I would like to thank my advisor Professor Joshua Eastin for his continuous support, insight, and suggestion throughout the writing of this thesis. It was an honor to have the collaborative opportunity and to be challenged to step outside of my academic comfort zone.

Secondly, thank you to Professor David Kinsella and Professor Birol Yesilada for serving on my defense committee and giving me the opportunity to demonstrate my knowledge.

Thirdly, to Sydney Rowe and Karen Richter for the grammatical editing assistance during the completion of my thesis. I wholeheartedly appreciate your help with this project. 


\section{Table of Contents}

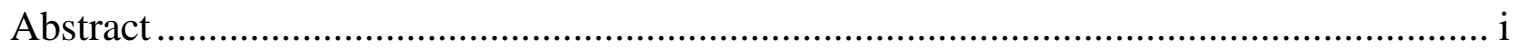

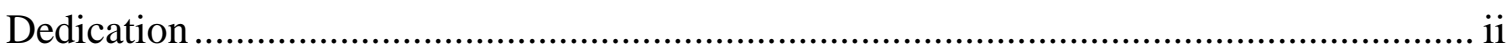

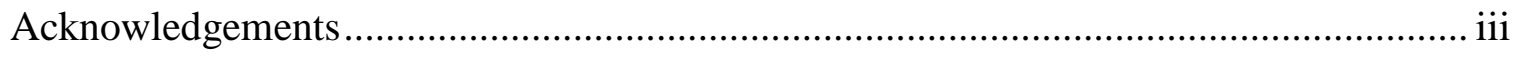

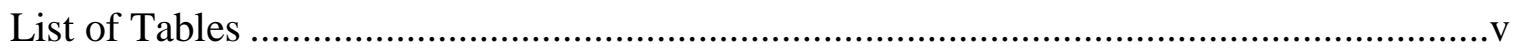

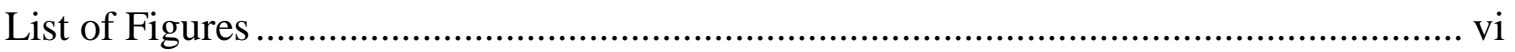

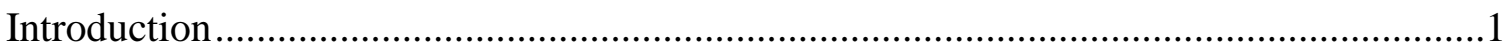

Chapter 1 Explaining the E-waste Problem .............................................................6

Why International Laws are Insufficient in Addressing the E-waste Crisis ..........11

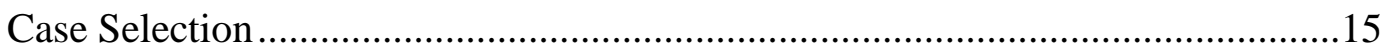

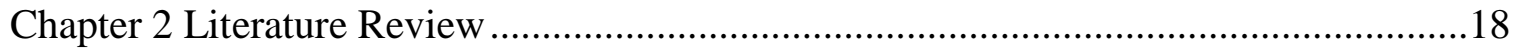

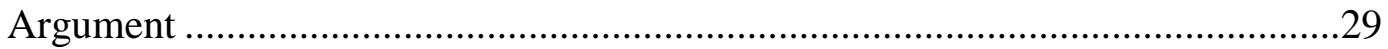

Chapter 3 Overview of Egypt, Nigeria, and South Africa ............................................

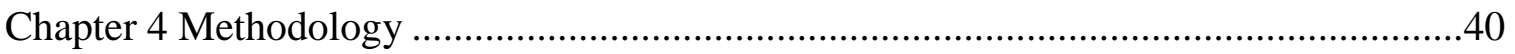

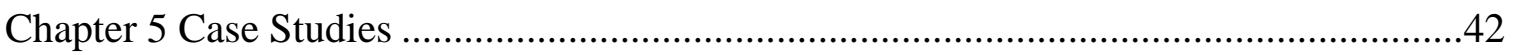

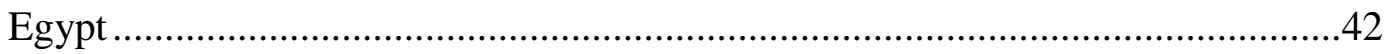

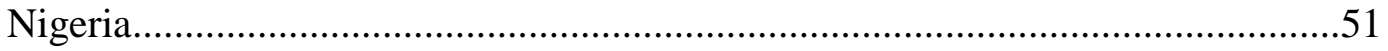

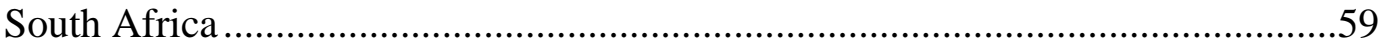

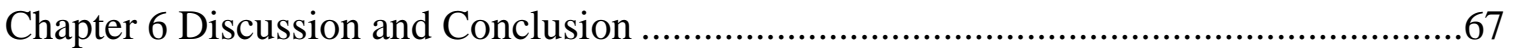

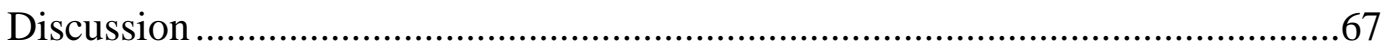

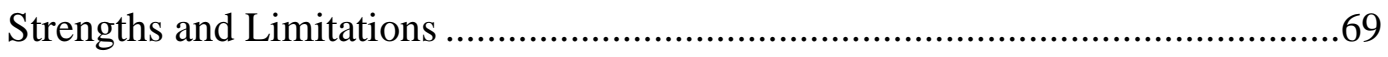

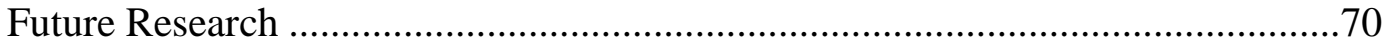

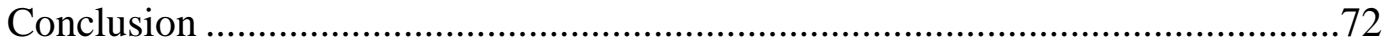

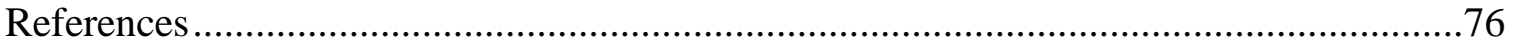

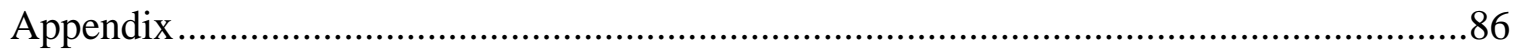




\section{List of Tables}

Table 1- US Consumer Electronics in Municipal Solid Waste Stream ............................7

Table 2 - Country Data Egypt, Nigeria, and South Africa...........................................33

Table 3- E-waste Repatriated by NESREA from 2010-2013 .................................. 58-59 


\section{List of Figures}

Figure 1 Egypt Imports by Product in US Dollars: Machinery and Mechanical Appliances and Electrical Equipment and Parts Thereof .............................................................. 31

Figure 2 Nigeria Imports by Product in US Dollars: Machinery and Mechanical

Appliances and Electrical Equipment and Parts Thereof ............................................32

Figure 3 South Africa Imports by Product in US Dollars: Machinery and Mechanical

Appliances and Electrical Equipment and Parts Thereof ............................................32

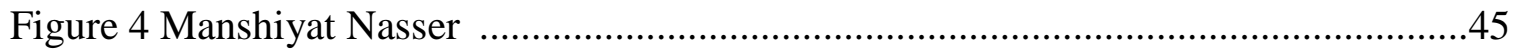




\section{Introduction}

Electronic waste (e-waste) is a growing and prevalent problem in the world with estimates of over 50 million metric tons generated each year. Yet, there is a substantial difference in the amount of e-waste generated and the amount of e-waste dumped within specific geographic regions. E-waste, in its simplest definition, is discarded electric equipment or products that have become obsolete. The developing world falls victim to the consequences of unregulated e-waste, and lacks the proper mechanisms to stymie it entirely. These less developed countries "create a 'perfect storm' for e-waste dumping: cheap and desperate labor with no added cost for health or safety regulations" (Vos, 2012). Developed countries tend to have sufficient legislation, efficient recycling techniques, and a more advantageous position in managing the negative aspects of ewaste spread, such as access to media to spread awareness, resources for more formalized methods of recycling and refurbishing, and the position of being distributors rather than the recipients of dirty goods.

We find more affected regions in South America, Southeast Asia, poorer port areas in China such as Guiyu in Guangdong Province, and in an expansive list of African countries. Suspected and known e-waste trade routes lead to major cities in Ghana, Nigeria, Egypt, and South Africa. There are millions of tons of e-waste being dumped into Africa each year compared to a small fraction of this number generated by African countries on the whole. This leads to the broader questions: Why is there such an extensive and expansive problem of e-waste in Africa; and, how does the nature of this problem compare to similar conditions across the globe? 
My primary research question for this study is: "What are the key factors influencing the proliferation of e-waste dumping in developing countries? My secondary, yet equally important inquiry is: What structures are emerging to combat the e-waste problem in Africa? I will briefly address a set of proliferating factors in an initial literature review, elucidate the factors exacerbating the problem in Africa, and expand upon the role of small and medium enterprises with case studies of Egypt, Nigeria, and South Africa. Furthermore, in a three-part case study I will give a general status of waste regulation and the e-waste situation, while honing in on major international corporations' engagement, the rise of small and medium enterprises (SMEs), and local nongovernmental organizations in Egypt, Nigeria, and South Africa. These key entities are either indifferent or urgently lobbying for changing the e-waste industry; both of these reactions are important to e-waste management and creating a thriving e-waste industry. The aim is to highlight the disjointed nature of these three major entities within the case countries. I will also illustrate how emerging local enterprises (often starting from grassroots organization) endeavor to manage the e-waste problem in their neighborhoods, and even their larger municipalities. The two sections will complement each other.

The primary factors driving e-waste dumping are illegal trade, poor regulation, lack of education and awareness (in the receiving nations), the incentive to export the dirty goods, and the broader pattern of obsolescence. The causes of the e-waste pandemic in Egypt, Nigeria, and South Africa are representative of an assortment of countries around the globe including but not limited to India, China, Mexico, and Colombia. These nations to different extents reduce their environmental and labor regulations in order to maintain a position in the global economy. 
I argue that the Pollution Haven Hypothesis $(\mathrm{PHH})$ - the proclivity of multinational corporations to relocate their operations to less environmentally regulated countries for financial savings - holds strong in Egypt, Nigeria, and South Africa as environmental regulations, though existent, are increasingly lax in all three countries. I contend that the Pollution Haven Hypothesis provides an important framework for why ewaste dumps are multiplying in Africa, but does not fully explain the phenomenon. Developed countries are offloading their waste with minimal repercussion. Egypt, Nigeria, and South Africa have all passed legislation that, on the surface, should control the influx of e-waste but they are not being enforced. I also argue that since e-waste is a pollution intensive industry, most of it will be dumped in the developing world as the PHH might predict. Although, Egypt, Nigeria and South Africa have the three largest economies in Africa, e-waste flows freely across their borders. Governments recognize that their citizenry, especially in the more urban areas, needs access to technology. This is increasingly true with the young adult population. Virtually all governments need to cut costs in order to have access to vital resources; e-waste is no exception. Race to the Bottom Theory (RTB) and the Pollution Haven Hypothesis have striking similarities in the African context, as well as globally. Therefore, my theoretical approach will apply RTB theory and PHH theory as a framework for explaining the proliferation of e-waste in African countries; Egypt, Nigeria, and South Africa.

While there might be incentives in place for multi-national firms, like Hewlett Packard, Nokia, and Sony, to engage in socially responsible cleanup efforts, the role of local SMEs is crucial because it provides opportunities for employment, boosts the local economy, improves the working conditions through formalized regulation, and in turn 
decreases the hazardous environmental impact of insufficient recycling methods. Finally, notions of environmental theories of justice (ETJ) and corporate social responsibility (CSR) are found more in the actions of small and medium enterprises (SMEs). Concerted efforts of major international technology companies such as Nokia to incorporate CSR into their business schemes have come post-factum. Legislation is not enough to tackle the e-waste problem. SMEs are starting to lead the front while multinational corporations are attempting to substantiate their reputations and be industry leaders is CSR efforts.

I suggest that SMEs are the key to successful e-waste management as the use of more primitive methods has proven grossly inefficient and hazardous to human health and the environment. As such, it is with extensive cooperative efforts from in house SMEs, various non-profit organizations, local associations, and the governments of each country that the e-waste problem can be regulated. Pollution havens will continue to exist as planned obsolescence sends e-waste to nations with mediocre regulations. The Race to the Bottom will remain, but my intention is to find evidence that suggests local SMEs as a structural solution to the e-waste problem, rather than a hindrance, to the African ewaste problem. The literature surrounding SMEs that concentrates on waste industries as a whole is pessimistic on the role of SMEs at best and finds that e-waste is seen as a nuisance. Therefore, my research will also be grounded in how the mission of SMEs dealing with e-waste is changing as the opportunities for local businesses are expanding. Adaptive management strategies continue to emerge through SMEs in developing nations. SMEs formalize the informal primitive and hazardous methods of dismantling, refurbishing and recycling. 
The first section of this study will focus on the e-waste problem as a whole, I will then give a brief overview of the measure of e-waste generation from developed countries like the United States and China and compare it to a smaller developing nation like Benin. There are major international coalitions and organizations diligently working to raise awareness and start e-waste initiatives but their efforts have slowly emerged. This will provide a necessary backdrop for how and why new grassroots level enterprises are forming in developing countries with major e-waste difficulties. In conjunction with these major co-ops, I will address the role of international legislation and conventions, such as the Basel Convention and its subsequent centers, located in a handful of countries, in halting the e-waste pandemic. Finally, I will provide a discussion of the definitions of ewaste and the role of informal and formal actors in an economic value chain. 
Chapter 1 Explaining the E-waste Problem

Defining e-waste enlists a broad range of materials. One such definition states, "ewaste encompasses a broad and growing spectrum of electronic and electrical devices ranging from large household appliances such as refrigerators, air conditioners to personal computers and cellular phones" (Azuka, 2009, p. 92). Widmer, Oswald-Krapf, Sinha-Khetriwal, Schnellmann, \& Böni (2005) provide an overview of waste electrical and electronic equipment (WEEE) incorporating definitions from major international organizations and prominent scholars. For the purposes of this study e-waste will be defined as any unwanted, inoperable, obsolete electronic product.

Oftentimes research focuses on the hazardous nature of e-waste, neglecting to address why e-waste dumpsites are erected in the first place, and how they accumulate thousands of metric tons year after year. An all-too-familiar system, which employs rapid technological advances with planned obsolescence, continues to pervade the hightech industry (Sullivan, 2014, p. 90). In short, technology is advancing faster than the human population's capacity to control it through both formal and informal methods, and it is cheaper and less laborsome to dump obsolete electronics and electronic equipment into developing nations. According to Ogunlade (2009/2010) e-waste follows a "path of least resistance" (p. 1). It starts from the negligence of the "dumping" country and ends with the mass accumulation in countries with weak and corrupt governments willing to take compensation for allowing such dangerous materials across their borders.

From Waste Management, we gather that the trend of e-waste disposal in the United States is increasing at an alarming rate. As Table 1 illustrates, the US disposed of 
$3,320,000$ tons of consumer electronic devices, nearly $1,500,000$ tons than the decade before (Waste Management, n.d., p. 1-2).

\begin{tabular}{|c|c|}
\hline Year & Amount in Thousands of Tons \\
\hline & \\
\hline 2000 & 1900 \\
\hline 2005 & 2630 \\
\hline 2007 & 3010 \\
\hline 2008 & 3160 \\
\hline 2009 & 3190 \\
\hline
\end{tabular}

Table 1 US Consumer Electronics in Municipal Solid Waste Stream ${ }^{1}$

There are conflicting opinions on the exact figures of United States' e-waste exports. In a PBS News Hour piece titled, Where Does America's E Waste end up? GPS Tracker Tells All, reporters express,

Estimates of U.S. e-waste exports vary widely. The United Nations says that between 10 and 40 percent of U.S. e-waste gets exported for dismantling. While the International Trade Commission - through a survey of recyclers - said in 2013 that a mere 0.13 percent of all used electronics collected in the U.S. went abroad for dismantling. (Campbell \& Christensen, 2016)

Even though measures vary widely, the lack of space for e-waste, more regulatory measures for recycling, and the general consensus that the United States should always have the most advanced technology all play into the outflow of obsolete electronics and electrical equipment.

Sullivan (2014) argues that in areas where there is mass urbanization and easy access to shipping ports, such as the city of Lagos, Nigeria, e-waste is more likely to be a destructive problem to urban sustainability. Yet, Sullivan (2014) fails to address how e-

\footnotetext{
${ }^{1}$ (Waste Management, n.d., p. 2)
} 
waste can be a constructive industry and enhance urban sustainability with sufficient planning and oversight. Computer Villages (the recycling centers), like that of Ikeja in Lagos, Nigeria are emerging with relative ease and with little regulation and oversight. As Francis Adeola (2011) notes, the movement of e-waste travels from the Global North to the Global South (p. 57), and less frequently in the other direction. With this in mind, it is imperative to look at major urban centers in West Africa as we tend to find e-waste dumping at its most severe in major metropolitan areas. E-waste poses major environmental degradation, threatens human health and well-being, and reinforces informal economies in poor countries, which further serves to divide the developed, and developing world. International intervention from nongovernmental organizations and international laws cannot solve the problem of e-waste alone. There are micro level and macro level phenomena interacting in complicated ways from international mandates to local grassroots scavenging. The e-waste crisis in Africa is no exception to this notion and needs to be addressed to prevent lingering effects on the human population and environment.

Over the last few decades e-waste has infiltrated other areas of the globe including major metropolises in China. China has been the dumping ground for $80 \%$ to $90 \%$ of the world's electronic waste (Jiang, 2009, p. 896). It has also registered the largest internal migration in world history, with more than 300 million people moving into cities. Additionally, there has been an influx of roughly 150 million rural migrant workers (Jiang, 2009, p. 893). These two notions are related in that, a larger influx of people generates greater technology use and need, and technology tends to be a major focal point in major metropolises attempting to grow economically and politically. The 
developing world relies on obsolete materials for this particular type of growth as it often lacks the mechanisms to build its own technologies. Additionally, in towns like Guiyua south-eastern province in China with a population of 150,000 - recycling is conducted in primitive ways. Primitive methods, like open and unregulated incineration, are often the source of inefficient infrastructure and government provided services which leads to dangerous health and environmental consequences.

On the other hand, countries such as Benin pale in comparison to China's population, gross domestic product (GDP), sheer geographical size, length of coastline, and the number of ports along their respective coastlines. Yet, Benin has a substantial ewaste problem of its own. It has, however, benefited from the work of MTN and Ericsson who held an e-waste drive that collected 20 tons of e-waste in a collection area. Benin's size and relative number of "dump sites" make this number compelling. If this measure is recognized as a small part of the larger, constant e-waste problem, it will leave the table open for discussion about the consequences that can come. MTN and Ericsson are two companies, among many, who are partnering to raise awareness about the environmental impact of e-waste in West Africa. In Benin, specifically, both companies are investigating the possibility--with the cooperation of the government and other stakeholders--of developing a long-term process to manage e-waste more sustainably in Benin (Company News, 2015). Benin's e-waste problem is disproportionate to its size. This might be due to the fact that more investment is found in nations with thriving international ports, and, more successful industry and businesses. Outside of Benin, Ericsson's focus is to: 
Provide product retrieval and safe disposal services for equipment that have reached its shelf life, as part the company's extended producer responsibility. Ericsson offers the program to all customers, guaranteeing that this e-waste does not end up in trade-restricted areas, landfill, or in places where unethical business practices are taking place. (Company News, 2015)

Coalitions between governments and international companies and organizations such as Canal plus, Diamond Bank, UNICEF, PNUD, SGS, SCB and Top Ingetract, and GreenPeace are vital for minimizing the negative consequences of e-waste. As they raise awareness, they educate the denizens of e-waste sites and citizens of the world.

Furthermore, they have the potential to compel states to engage in transparent trade relations if international pressure is sufficient. This insight provides one method for countries to combat e-waste persistence, in that the aforementioned bodies have the potential to act as a buffer to e-waste growth over the next decades. These entities have the ability to help struggling developing countries find solutions to e-waste dumping. The resources (monetary, human, services), the social acknowledgment and exposure, academic studies, etc. that these organizations provide can all go into successful e-waste management.

There are a handful of regions around the globe that are not afforded this type of coalition building and civic participation which allows the continual buildup of e-waste, in light of burgeoning international awareness surrounding the issue. In more autocratic states, notions of coalition building and civic participation do not dominate the political and social discourse, especially surrounding sustainability and its effect on humans and the environment. Therefore, internal mechanisms do not have the ability to combat a phenomenon that affects the social, political, environmental, and ecological atmosphere 
of a country. In democratic states, places where there are strong ties to the environment, green political thought takes a higher priority in social and political discourse.

Why International Laws are Insufficient to Address the E-waste Crisis

International legislation and international awareness surrounding electronic waste and hazardous waste in general have increased within the last 30 years. The Basel Convention on the Control of Trans-boundary Movements of Hazardous Wastes and Their Disposal (Basel Convention) was signed in March of 1989 and enforced in May of 1992. In the 1980s, the search for cheaper disposal of waste resulted in shipment of hazardous waste to developing countries and Eastern Europe (United Nations Environment Program and Swedish International Development Agency, n.d, p. 4). Within the first decade of the Basel Convention, from 1989 to 1999, members developed a framework for controlling transboundary movements and developed criteria for environmentally sound management (ESM) (United Nations Environment Program and Swedish International Development Agency, n.d, p. 17).

With 170 member countries, [the Basel Convention] aims to protect human health and the environment against the adverse effects resulting from the generation, management, trans-boundary movements and disposal of hazardous and other wastes (Secretariat of the Basel Convention, 2014). The Basel Convention's main objective is to ban exports of hazardous wastes for final disposal, recovery, or recycling from States listed in Annex VII (mainly OECD countries) to States not listed in Annex VII (mainly non-OECD countries) of the Convention (Basel Convention, n.d.). 
Following the Basel Convention's initial 10-year commencement from 1989 to 1999, the subsequent decade from 2000 to 2010 focused on partnerships, cleaner technologies and production, reduction of hazardous waste movement, prevention and monitoring of illegal traffic, improvement of institutional and technical capabilities in developing and EIT countries, and training and technology transfer in regional and subregional centers known as BCRCs. Since 1989, the mission and goals of the Basel Convention have remained consistent, with bodies only adding aims that further reinforce the initial aims.

In conjunction with the Basel Convention, there are affiliated agreements such as the Basel Protocol on Liability and Compensation for Damage Resulting from Transboundary Movements of Hazardous Wastes and their Disposal. This particular protocol "provide[s] for a comprehensive regime for liability as well as adequate and prompt compensation for damage resulting from the transboundary movement of hazardous wastes and other wastes, including incidents occurring because of illegal traffic" (United Nations Environment Program and Swedish International Development Agency, n.d, p. 23). Unfortunately, the number of signatories needed to enter this protocol into force is still short of the designated amount; 20 ratifications are needed, there are 13 signatories and 11 parties to the convention (Basel Convention, 2011). Swingler (2014) states that the Basel Convention "makes the movement of e-waste to countries that have not consented to that movement illegal, but imposes neither liability nor punishment." The extent to which countries adhere to the agreement needs to be questioned continuously, and a stronger accountability mechanism needs to be in place 
for those nations party to the convention as well as those countries not participating in the convention that engage in the export and import of used electronics.

The Basel Convention also includes Regional Centers for Training and Technology Transfer (BCRC). BCRCs “provide guidance on technical, technological issues, legal issues as well as advice on enforcement aspects of the Basel Convention and related Conventions like Stockholm, Rotterdam and Montreal Protocol" (United Nations Environment Program and Swedish International Development Agency, n.d, p. 19). Other aims include the encouragement of environmentally sound management practices and the enhancement of information exchange, education, and awareness-raising (United Nations Environment Program and Swedish International Development Agency, n.d, p. 20). Three major BCRCs are located in Egypt, Nigeria, and South Africa. BCRC's ultimately act as hubs or incubators for the integration of various ideas and best practices surrounding hazardous waste management. The utility of these centers is under researched and should be included in a broader discussion of transnational e-waste management including the countries in North America.

The main argument for disagreement from opposing countries (such as Australia, USA, and Canada) is that the Basel Convention is inconsistent with the General Agreement on Tariffs and Trade and ultimately trade-disruptive (United Nations Environment Program and Swedish International Development Agency, 2004, p. 21). The United States has not ratified the Basel Convention, a decision with disagreements occurring along economic and political lines; that is, environmental and industry groups see the treaty as inadequate and burdensome to sufficiently and efficiently reduce the amount of hazardous waste worldwide. One argument against the treaty is that "some 
developing countries, especially in Asia, may have better capacities for environmentally sound management of wastes than certain OECD members" (BioRes, 2004). As with any treaty, there will be blatant cases of insubordination. As such, "a ban would most likely not resolve cases of illegal traffic in hazardous waste nor assist in the creation of waste treatment and recycling capacity in developing countries" (BioRes, 2004). Furthermore, critics also question the need for the ban as the Convention already allows countries to prohibit the import of any waste they declare hazardous under domestic legislation (BioRes, 2004).

As an extension of the Basel convention specific to the African continent, the Bamako Convention was introduced and entered into force in 1998 roughly a decade after the Basel Convention. Ogunlade (2009/2010) argues that the,

Flagship difference between the Basel and Bamako Conventions is the outright ban imposed by the Bamako Convention on the import of hazardous wastes into Africa. Article 4(1) specifically obliges parties to take appropriate legal, administrative and other measures within their jurisdictions to prohibit the import of all hazardous wastes, for any reason, into Africa from non-contracting parties, and that all such imports shall be deemed illegal and criminal. Prohibition 'for any reasons' encapsulates the hitherto notorious escape route of sham recycling. (p. 9)

Aside from the Basel and Bamako Conventions, there are international bodies which take a more practical approach to e-waste. Over the past decade the number of partnerships and initiatives including e-waste in their agendas has increased. These coalitions are incorporating both developed and developing countries in the discussion and attempting to look at the problem from both internal and external vantage points. Tackling the global e-waste problem on the ground — rather than through armchair theorizing-is crucial. 
Despite being a party to the Basel Convention, and Bamako Convention, and regardless of the growing number of internationally based initiatives trying to tackle the e-waste problem, Egypt, Nigeria, and South Africa still have large and growing e-waste problems. In these countries, the e-waste problem is driven by a number of strong internal factors as well as complex foreign relationships that scholars have not analyzed sufficiently. Some brief explanations for this phenomena are: trade laws are violated by both exporting and importing countries, recycling services in the informal and formal sector are inefficient, and the respective governments are not held accountable to their legal decisions in signing treaties or agreements.

\section{Case Selection}

In order to conduct a comparative study on the nature of e-waste within Africa, I will concentrate on a specific set of countries where e-waste dumping is tremendous and the dangers are increasingly apparent compared to other nations in the continent. I am choosing to conduct a qualitative analysis to investigate the nature of the e-waste problem in Egypt, Nigeria, and South Africa. Qualitative data allows the researcher to conduct an in depth examination of a variable that may be harder for quantitative analyses to address, or that may be obscured by quantitative methods. Assessments that have been conducted on West African countries such as Ghana and Nigeria provide a solid framework from which to work. That is, these assessments provide a set of guidelines from which to analyze the roles of businesses, individual stakeholders, and the government.

Furthermore, the investigations show what research is lacking in the e-waste literature. Other investigations in Brazil and India reveal the issues within informal economies. 
One study on Ghana demonstrates EEE imported into the developing world, by

percentage, is more often than not unsellable and unusable. In Ghana,

About $30 \%$ comprised of new products and $70 \%$ second-hand EEE. Around $15 \%$ of the second hand imports was estimated to be unsellable (i.e. would not respond to power, broken or outdated), a significant portion of which was destined directly to informal recycling. Another $20 \%$ of the imports can be serviced (repaired/refurbished) to get them functioning. (Amoyaw-Osei, Opoku, Pwamang, Mueller, Fasko, \& Schluep, 2011, p. x)

In one e-waste assessment on Nigeria, Manhart, Osibanjo, Aderinto, \& Prakash (2011) look at the "socio-economic nature of the functioning and sustainability impacts of the informal EEE-refurbishing and e-waste recycling sector in Lagos, as well as a comparison of currently practiced and best available recycling technologies" (XI).

In a multi-country assessment of e-waste management the International Labor Organization (ILO) states, "informal workers and entrepreneurs entering the e-waste market either come with a background in (solid) waste picking and recycling, or come from other backgrounds and are attracted to this sector due to the relatively recent growth in demand for secondary raw materials (ILO, 2014, p. 33). The ILO found that these same informal workers "remain unaware of the many materials and products that could also be retrieved and recycled" (ILO, 2014, p. 33). These waste pickers are in constant competition with more formalized companies for access to better technologies, networking, and seemingly safer environments. The dilemma arises as these professional enterprises need access to the actual stores of e-waste. Bridging the formal and informal sectors could achieve major social welfare objectives by reducing environmental hazards and health risks, improving resource management, and creating green jobs (Raghupathy, Krüger, Chaturvedi, Arora, \& Henzler, 2010, p. 2). Study of the Chintan organization in 
India reveals that workers unions and partnership between collectors/dismantlers and companies helps to expand extended producer responsibility. Chintan also proposed a solution that involves "the establishment of an industrial park for e-waste trading and dismantling, with the state providing the land and the producer and retail companies financing infrastructure, transportation, technological innovation and training (ILO, 2014, p. 33).

In total, the studies often focus more on the consequences of the e-waste trade such as environmental impact, poverty reinforcement, and health side effects and to a lesser degree its benefits in terms of development. Generally, researchers look at the ewaste problem through categorical roles such as consumers, collectors, and repairers depicting where and how they act in controlling and handling electronic equipment as well as e-waste. A significant portion of these assessments provides "best practices" for e-waste management. These investigations, through fruitful, only touch the tip of the iceberg when it comes to explicating the actual causes of e-waste proliferation. The nature of the study at hand will center on providing a new, extending angle to e-waste country assessments that are incomplete, adding the dimensions of corporate responsibility, economic incentive, and environmental theories of justice.

The following pages will include a literature review of current theories and research that can serve as a backdrop to addressing the e-waste pandemic. 


\section{Chapter 2 Literature Review}

Nnorom and Osibanjo (2008) argue that even with e-waste management practices and sound legislation, governments frequently neglect to apply protocols and enforce regulations. Governments need to change their apathetic attitude. Additionally, Sullivan (2014) provides a list of variables that can be tracked within the West African region, which are not limited to Nigeria, the focus of his study. Sullivan (2014) comprised a list as follows: low shipping costs, cheap labor, lack of economic diversification, ambitions for increased access to ICT, weak environmental protection laws and regulations-in agreement with Nnorom and Osibanjo 2008 — and the failure of government to develop an environmental ethos that recognizes the rights of the people to a healthy landscape (p. 99). There is some suggestion that education levels of the political elite and the general public strongly effect whether e-waste management is successful. I will investigate whether education, awareness, and to a certain degree civic participation, will play a huge role in whether a country can halt the escalation of e-waste within its borders. And these will become major focal points for small and medium sized enterprises with each of my case study countries.

Malakata (2015) argues that recycling programs are stronger in East Africa and South Africa, though they do function with some difficulty. One of the main initiatives in Egypt is run by a "youth incubator hub...supplemented by activities to develop sustainable framework conditions through policies, financing mechanisms and standards setting” (World Resources Forum, 2015). Schluep (2010) addresses EMPA a Switzerland based e-waste management program that provides analysis of and aid to developing countries suffering from the various consequences of e-waste. He provides 
detailed diagrams of where various countries fall on the continuum of informal/formal sector e-waste management. One of his main arguments posits that countries with weak informal economies and strong formal economies have a relatively easier time managing e-waste which is one distinction between the nature of e-waste in countries such as Ghana, Liberia, Nigeria, Ivory Coast, and Senegal. This should provide a platform for understanding the different factors that contribute to emergence of e-waste sites in Africa. The "illegal import of e-waste or used electronics from all over the world is a major source of e-waste in countries like Ghana and Nigeria" (Baldé, Wang, Kuehr, \& Huisman, 2015, p. 38). Schluep (2010) also claims that developing countries are seriously affected, since they produce a growing amount of e-waste by themselves, some receive e-waste from industrialized countries, they have many cheap and unskilled workers, and they face a lack in suitable laws and their enforcement (p. 2).

Ogunlade (2009/2010) stresses that hazardous waste travels along the path of least resistance, and it is worsened by corrupt and weak political leadership in these countries. State officials in these systems are easily compromised "with bribes to the detriment of the health of its citizens and protection of its environment" (Ogunlade, 2009/2010, p. 1). This assertion provides a strong parallel to RTB theory. RTB theory posits that competition between companies and countries for economic success leads to the moving of their operations overseas. Companies move their businesses to the developing world to reduce overall costs as many poorer nations seek to invest in international trade. However, international competition is increasing and in order to compete the developing countries have to reduce their standards of living, and relax their labor, environmental, and tax regulations (Quak, 2015). Pertaining to e-waste, Egypt, Nigeria, and South 
Africa obtain the obsolete products of major companies like Dell, Apple, Samsung, and Hewlett Packard as supposed donations, at incredibly cheap prices, or through the illegal dumping of the ICT goods. The dumping of e-waste in nations with poor environmental and labor regulations is advantageous for dumping countries like the United States. In conjunction, to become a strong political actor, or solely to acquire more capital, government leaders often sacrifice the health and wellbeing of their own citizens for personal gain. In the most positive light, political leaders prioritize what issues to address and to what extent. Dirty industries thrive in areas where the environment regulation is minimally enforced. It is increasingly important to pressure government leaders to be held accountable for their actions and for providing basic human rights to the citizens and residents of their countries. There is, however, a need to investigate how competition within the e-waste market might benefit the developing world and hinder the proliferation of the e-waste problem. The e-waste problem has the potential to be addressed more fully worldwide with strong political and economic development and ongoing discussion.

Furthermore, for the framework of this study it is crucial to take this notion of hazardous waste following a path of least resistance and incorporate it with a modern stance on Immanuel Wallerstein's World System Theory (WST). Wallerstein posits that the world is comprised of nation states interacting within a capitalist world economy; these nation states are categorized as being a part of the core, semi-periphery, or periphery. The core states are the most developed and geographically advantaged countries namely those in North America and Europe as well as Australia and Japan, semi-periphery states such as Mexico, Brazil, and South Africa play an intermediate role between the core and periphery as they normally have sizable markets, a supply of 
valuable resources, and continue to grow their industries. The periphery states are the least developed nations of the world dependent on the core for capital. If we think of Egypt, Nigeria, and South Africa semi peripheral countries, it broadens our lens in which to view the e-waste problem. That is, Egypt, Nigeria, and South Africa are intertwined in a complex system of trade, exploitation, and a certain degree of government corruption and they have industries that can and need to be developed to boost their economies and place in the global hierarchy. They also export their goods to core and periphery nations. Yet, they undeniably fall into the category of the Global South when compared to the power of Europe and North America.

Adding to WST, Race to the Bottom Theory (RTB) is also a necessary lens from which to view the e-waste problem. WST and RTB theory are profoundly interconnected. Economic globalization has left the door open for developed nations to engage in a web of interactions that allow for the exploitation of developing countries vital resources and money. Rudra (2008), states,

According to this hypothesis, a world increasingly free of restrictions on trade and capital flows allows investors to scour the globe in pursuit of the highest rate of returns. Nations that harbor public policies that raise production costs or inhibit sound macroeconomic fundamentals risk lower profit margins and capital flight. Fearing such reprisals, governments are constrained from initiating (or maintaining) policies that guarantee a higher quality of life for their citizens, such as safety nets, environmental standards, and acceptable labor costs and protections. (p. 2)

The electronics trade is one of many aspects of globalization that links strongly to the tenets of RTB theory. As the electronic waste trade burgeons, so too will the demand for control over its potential profits in developing countries. There is an increasingly evident economic incentive in monopolizing major dumping areas. The growing e-waste 
problem not only substantiates the merit of RTB theory but also challenges its boundaries. That is, competition does not depend on scarce investment flows, but rather the nature of dominating an industry that is growing faster than its capacity to be controlled. There is no dearth of e-waste in the developing world and more developed nations like China and the United States can gain from the emerging competition. Obsolescence does not automatically equate to defective or damaged products. The quality of life and the detrimental effects of lax regulation are obvious in the global bottom. But the potential gains from capital investment stem from framing toxic waste as a necessary part of sustainable economic development. E-waste can benefit the receiving country if it is highly regulated and seen as an enterprise, and not exclusively as an environmental injustice.

Thirdly, as a complement to RTB theory, the Pollution Havens Hypothesis (PHH) asserts that,

Differences among countries in environmental standards and costs cause relocation of economic activity especially dirty industries from strictly controlled countries to those with few or no standards by creating 'pollution havens' for developed countries. That is, pollution havens occur when dirty industries move from countries with stringent environmental regulations to countries with weak regulations. (Akbostanci, Tunç, \& Türüt-Asik, 2007, p. 298)

E-waste dumpsites then become pollution havens as the regions where electronic goods are manufactured and used neglect to adequately treat the polluting products (Tong \& Wang, 2004, p. 590).

The PHH asserts that international trade does not have a benign environmental impact. As such, Taylor (2004) finds that the PHH is hotly debated and calls for a distinction between the Pollution Haven Effect (PHE) and the Pollution Haven 
Hypothesis. For Taylor, the PHE "arises when a tightening of environmental regulation deters exports (or stimulates imports) of dirty goods" (2004, p. 4). Thus, for Taylor (2004), it is the summation of multiple PHEs that constitute an argument for the PHH; in fact Taylor (2004) adds, "at present we have very little empirical evidence linking openness to markets, pollution levels, and technology choice" (23). It follows that,

Estimating the strength of pollution haven effects is still of great value: failure to find them implies failure of the Pollution Haven Hypothesis; and finding only small effects is also suggestive evidence against the hypothesis. (Taylor 2004, 4)

The research on the PHH and its subsequent components PHEs has taken a limited look at the role of SMEs and non-profit organizations in so called pollution havens. On a much larger scale "it is undeniable that some multinationals, put the position of profitability above their environmental responsibility" (Bu, Liu, Wagner, \& Yu, 2013, 86). Regardless,

This is surprising because it is widely believed that technology transfer to poor developing countries will help them limit their pollution levels regardless of the stringency of their pollution policy or their income levels. If the diffusion of clean technologies is accelerating as a result of globalization, this indirect impact of trade may well turn out to the most important for environments in the developing world. (Taylor, 2004, 23)

This mixed bag of empirical results calls for a more intensive investigation of internal market regulators, specifically SMEs and foreign firms. The PHH is for Taylor (2004) and Copeland and Taylor (1994) a positive phenomenon while environmental dumping presents the antithesis having a negative welfare implication. Whether the PHH will present a negative case in relation to e-waste is yet to be concluded. 
For the purpose of this research the e-waste problem adds another layer to the mixture of perspectives surrounding the PHH. SMEs and larger multinational corporations have the potential to be a significant hindrance to the proliferation of ewaste. Eskeland \& Harrison (2003) find no evidence in support of the PHH in their study on foreign direct investment patterns in Cote D'Ivoire, Mexico, Morocco and Venezuela. Their research finds that "foreign firms are less polluting than their peers in developing countries" (2003, p. 22). Additionally, they argue most research on "pollution havens" is anecdotal and qualitative, ignoring the statistical correlation or lack thereof "between the distribution of...foreign investment and pollution intensity" (Eskeland \& Harrison, 2003, p. 2). My research will attempt to evaluate the PHH through three cases studies on local and foreign enterprises working in Egypt, Nigeria, and South Africa.

Finally, corporate social responsibility is intrinsically linked to the e-waste problem and its potential solutions. According to the United Nations Industrial Development Organization (UNIDO) a basic description of corporate social responsibility follows the process of companies integrating social and environmental concerns in their business operations and interactions with their stakeholders (United Nations Industrial Development Organization, 2017). CSR is generally understood as being the way through which a business achieves a balance of economic, environmental and social imperatives, while at the same time addressing the expectations of shareholders and stakeholders (UNIDO, 2017). The e-waste problem has fostered a competitive scrapping and recycling industry in the countries that attempt to salvage obsolete goods. 
Accountability and transparency are key strategies by which businesses can meet corporate social responsibility standards. Corporations that sell technology such as cell phones, televisions, computers, and refrigerators, are responsible for the impact their business has on a local and global scale. Proponents of CSR contend that sustainable development, increasing profit, creating jobs, limiting environmental degradation and damage through reasonable use of natural resources, and providing for societal needs are imperative to a synergistic and holistic business. Opponents maintain that unless the actions of the business result in profit maximization, it is inefficient and a waste of resources to engage in activities that address social predicaments or ecological maintenance.

Cowper-Smith \& De Grosbois (2011) look at CSR in the airline industry. They conclude that airline companies show a stronger focus on environmental issues than on the social or economic dimensions of CSR and that the airline industry is making strides incorporating environmentalism into their major business initiatives. These companies are not only espousing a commitment but also proactively addressing the need for greener technology and reporting their results. Truthfully, as environmentalism is normalized, adopting greener practices fashions a more positive public image for airlines. This notion, can and should be addressed in the context of e-waste and the companies that continue to make electronics that inevitably become obsolete.

In contrast, Friedman (1970) takes a more conservative, shareholder approach to CSR stating it is counter-intuitive and undermines best business practices. CSR, for Freidman is only justified "when there is one and only one social responsibility of business-to use its resources and engage in activities designed to increase its profits so 
long as it stays within the rules of the game, which is to say, engages in open and free competition without deception or fraud" (1970, p. 6). CSR proponents would argue that the SMEs and multinationals have a moral responsibility to limit the negative social, ecological, and political impact their technologies create in the developing world. Moreover, local startups are employing CSR to combat the e-waste problem at home, as shown in the subsequent case studies. CSR cannot be avoided in the e-waste context, lest the pandemic continues to grow. Friedman (1970) is decidedly challenged by the role that globalization has played in dirty industries.

It is also crucial to understand what drives the decision making process of certain companies and what makes them select their locale of influence. The reasoning behind social and environmental action is intertwined in the influence of CSR particularly when corporations have the resources to choose where their time and energy will go. For example, Hewlett Packard over the past decade has increased its involvement in places where technology use has grown at alarming rates especially in North Africa. As this involvement has increased, executives have had to decide how technology will affect nations over time as resources are plenty, but not infinite. The limits of CSR are shown in its intersection with market capitalism and profit maximization.

According to Archie Carroll, CSR is both ubiquitous and ambiguous at best. According to Votaw (1973), (as cited in Carroll, 1999):

The term [social responsibility] is a brilliant one; it means something, but not always the same thing, to everybody. To some it conveys the idea of legal responsibility or liability; to others, it means socially responsible behavior in an ethical sense; to still others, the meaning transmitted is that of "responsible for," in a causal mode; many simply equate it with a charitable contribution; some take it to mean socially conscious; many of those who embrace it most fervently see it as a 
mere synonym for "legitimacy," in the context of "belonging" or being proper or valid; a few see it as a sort of fiduciary duty imposing higher standards of behavior on businessmen than on citizens at large. (p. 280)

In regards to the realm of e-waste management, it is imperative that all possible tenets of CSR are incorporated to understand fully the e-waste problem in the developing world.

In grappling with the e-waste problem incorporating theories of protective justice are notably important. Mascarenhas, D’Souza \& George (2016) stress that post factum responses to the e-waste problem are ultimately disadvantageous as the damage done is often irreversible and the solutions are essentially a band-aid; the problem mutates over time (p. 1). They state,

Prevention is better than cure. Preventive and protective regulation is more effective than post-factum control regulation of e-waste tonnage. Preventive regulation should be grounded on preventive justice theory and ethical and moral rules, and protective regulation should be founded on protective justice theory and moral rules and standards. (Mascarenhas, D’Souza \& George, 2016, p. 2)

This two part justice theory is closely linked to CSR. According to Mascarenhas, D’Souza \& George (2016), “one of the most promising policy options to address this issue is to extend the producers responsibility for their products beyond the point of sale, until the end of product life" (p. 4). Though the literature is limited on a shift from post factum response to preemptive, there are scholars that acknowledge the changing tide in environmental management. Rondinelli (2004) expresses, "many have progressed from a strategy of avoidance minimal compliance with regulations to one of pro-active voluntary environmental management that exceeds legal requirements" (p. 5). Ultimately, there can be an ethical economics involved with e-waste management; there must be. 
The limited literature on the interaction of SMEs with e-waste is relatively pessimistic. In fact, Heeks, Subramanian, \& Jones (2015) find that e-waste is an almost nonexistent subject on most SME's management agendas. Most SMEs meet the e-waste problem with a stance of indifference (Heeks Subramanian, \& Jones, 2015, p. 659). Even more pressing is the realization that most SMEs (in contrast to larger national and international corporations) are unaware of either existing rules and guidelines or forthcoming legislation (Heeks et al., 2015, p. 659). Larger ICT firms file compliance reports, but SMEs "being exempt from any environmental oversight, these issues were simply not "on their radar" (Heeks et al., 2015, p. 659). SMEs, according to Heeks et al. (2015) are largely invisible to government, the mass media, and their general potential client base, and they tend to work through direct relationships (p. 660), although it is ironic and against the literature of CSR for SMEs to maintain and attitude of indifference on the matter of e-waste. Heeks et al. (2015) concludes,

For the SMEs, e-waste is a peripheral nuisance; something on which to spend minimum effort in exchange for as much of a financial payment as can be extracted from their current connections to dealers in either ICT or scrap. Lacking any perceived contextual pressures, SME managers vest in e-waste no wider business or social or environmental ramifications. (p. 662)

Finally, understanding that there are economic incentives to the e-waste trade will help to explain why certain enterprises elect to partner with government coalitions and international corporations as well as expand their business opportunities. In the United States alone the "electronics waste recycling is a \$20 billion industry with the potential to employ thousands, while reducing negative environmental impact of waste" (Smith, 2015). Bu et al. (2013) state, "on the contrary for some multinationals environmental responsibility takes priority and they never lower their environmental standards in pursuit 
of a higher profit rate" (p. 86). Additionally, Bu et al. (2013) attempts to juxtapose CSR and the PHH by investigating the relationship between local environmental regulation and the location choices of foreign firms (p. 86). Rondinelli (2004) also links the economic and social pursuits of CSR with the PHH; that is, multinational corporations seek to adhere to environmental sustainability while achieving business advantages (p. 5).

\section{Argument}

Since WST describes semi-periphery nations as having sizable markets, a supply of key resources, and a surge in market growth, it follows that Egypt, Nigeria, and South Africa can and will utilize the massive e-waste industry as a means to snowball their economies and improve their position in the global economy. With all of these paradigms and theories in mind, I expect to find small and medium enterprises (SMEs) adopting notions of CSR and environmental theories of justice. The aim is to present SMEs as simultaneously searching for more business opportunities as well as incorporating the importance of ethical business models that take into account the important of labor rights. Moreover, I also predict that larger international corporations will adopt to different extents the tenets of CSR as well as EPR. The perspective of Mascarenhas, D'Souza and George (2016) should serve as a catalyst for policy change as "all problems of waste, ewaste in particular, are man-made, and need man-initiated, man-volunteered solutions. That is, e-waste solutions, besides being legal and economic, need to be ethical and moral, and even spiritual" (p. 2).

It has taken more than two decades worth of prematurely retiring electronic goods for companies to be held accountable for their lack (often intentional neglect) of CSR and 
EPR. The burden has been placed on those living in and around the squalor of e-waste markets. Luckily there have been entrepreneurial endeavors within developing countries to create a means of subsistence and resistance. A distinction needs to be made between what major corporations are doing within Africa acting alone, what local SMEs are doing without the help of major corporations, and the few interactions of positive partnership. There is a lot of ground to cover in the combattance of e-waste in the developing world and I expect to find instances of all three in my subsequent case studies. Even though a plethora of information exists on e-waste, the literature is incomplete. My research will add to the conversation. 


\section{Chapter 3 Overview of Egypt, Nigeria, and South Africa}

In choosing Egypt, Nigeria, and South Africa as my three case studies, I hope to explicate the specific causes of e-waste growth in these three areas as these nations have on the one hand seemingly similar demographics and on the other hand key differences. The EEE import statistic differs between Egypt, Nigeria, and South Africa. Overall, over roughly a five year time span, the imports have increased for all three countries. In the three graphs below we can see this contrast:

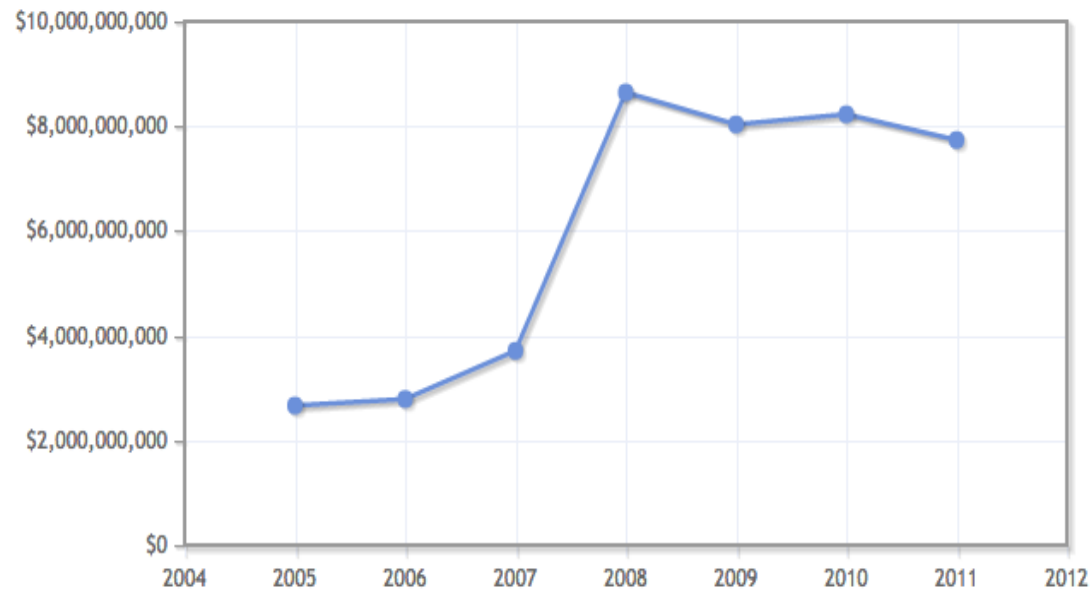

Figure 1 Egypt Imports by Product in US Dollars: Machinery and Mechanical Appliances and Electrical Equipment and Parts Thereof ${ }^{2}$

${ }^{2}$ IndexMundi, 2018a 


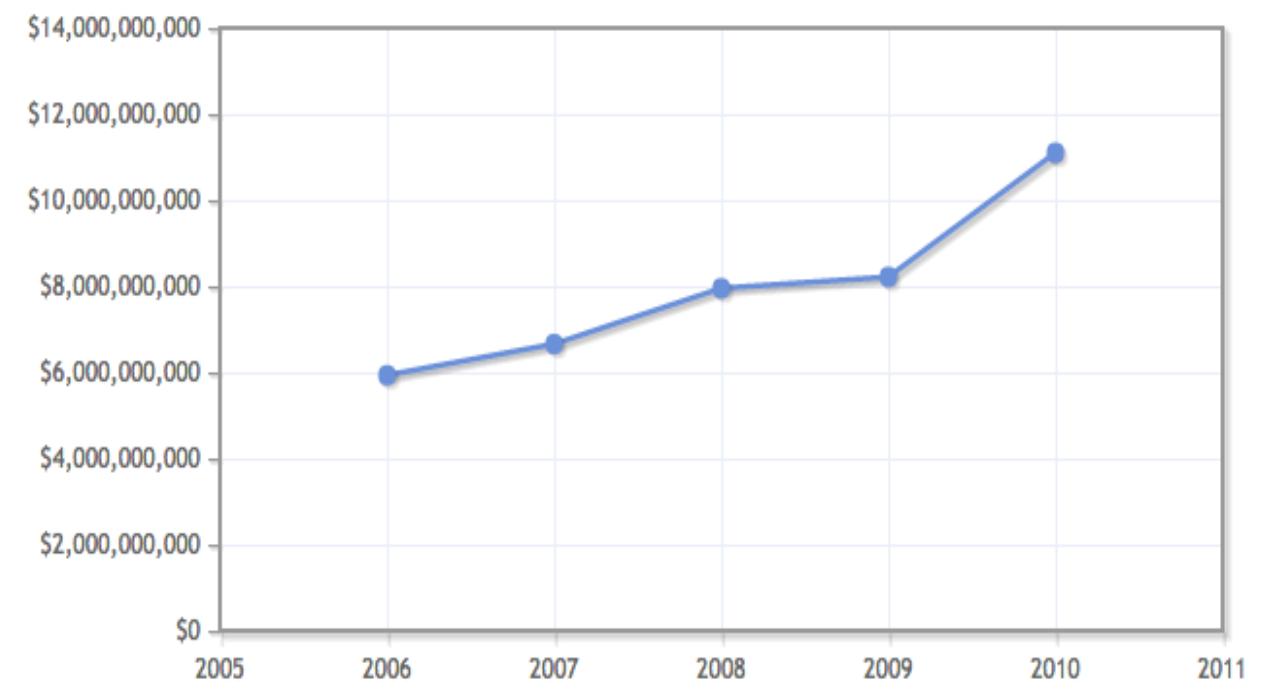

Figure 2 Nigeria Imports by Product in US Dollars: Machinery and Mechanical Appliances and Electrical Equipment and Parts Thereof ${ }^{3}$

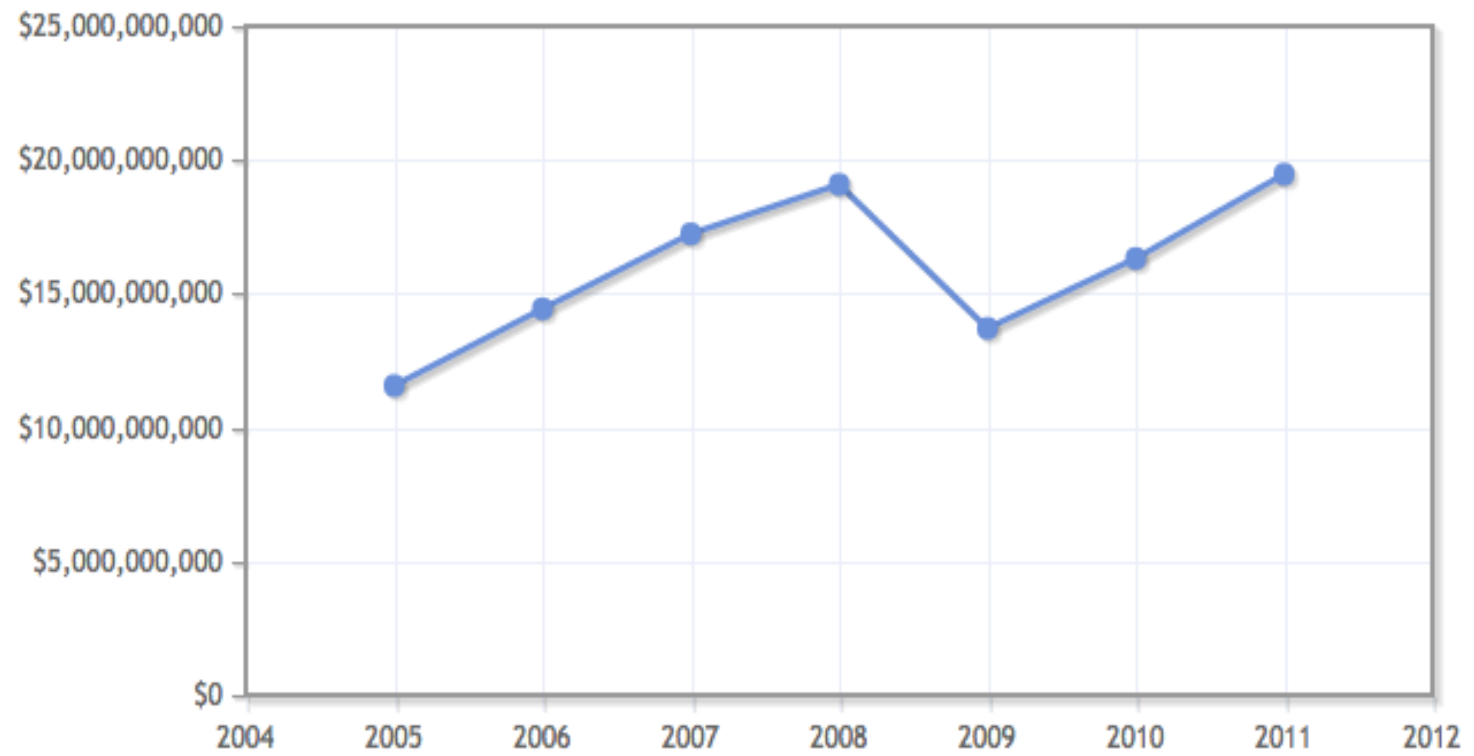

Figure 3 South Africa Imports by Product in US Dollars: Machinery and Mechanical Appliances and Electrical Equipment and Parts Thereof ${ }^{4}$

${ }^{3}$ IndexMundi $2018 b$

${ }^{4}$ IndexMundi 2018c 
The Index Mundi statistics show a growth trend. That is, over a period of almost a decade Egypt, Nigeria, and South Africa have increased their importing of electrical equipment. These are the documented imports, and reporting does not account for devices received illegally. It does, however, affirm that ICT products are crossing the borders of Egypt, Nigeria, and South Africa at an alarming rate which leads to more e-waste.

With this in mind, additional data gathered from various online indices shows Egypt, Nigeria, and South Africa are relatively close in measures pertaining to international positioning in regards to waste legislation, GINI index, literacy rate, government type, purchasing power parity, and labor force participation. Below is a simplified table of comparison:

\begin{tabular}{|c|c|c|c|}
\hline & Egypt & Nigeria & South Africa \\
\hline Population & $\begin{array}{l}96,382,900(2017 \\
\text { est.) }\end{array}$ & $\begin{array}{l}\text { 185,989,640 (2016 } \\
\text { est.) }\end{array}$ & $54,300,704$ (2016 est.) \\
\hline $\begin{array}{l}\text { Party to International } \\
\text { Legislation on Hazardous } \\
\text { Waste }\end{array}$ & yes & yes & yes \\
\hline $\begin{array}{l}\text { Party to the Basel } \\
\text { Convention }\end{array}$ & yes & yes & yes \\
\hline Government Type & Republic & Federal Republic & Republic \\
\hline $\begin{array}{l}\text { Purchasing Power Parity } \\
\text { (US Dollars Per } \\
\text { Inhabitant) }\end{array}$ & $\begin{array}{l}\text { \$1.173 trillion } \\
\text { (2017 est.) }\end{array}$ & $\begin{array}{l}\$ 1.24 \text { trillion }(2017 \\
\text { est.) }\end{array}$ & $\begin{array}{l}\text { \$742.46 billion (2017 } \\
\text { est.) }\end{array}$ \\
\hline Labor Force Participation & $50 \%$ (as of 2016) & $56 \%$ (as of 2016) & $53 \%$ (as of 2016) \\
\hline Urbanization & $\begin{array}{l}43.1 \% \text { of total } \\
\text { population }(2015 \\
\text { est.) }\end{array}$ & $\begin{array}{l}43.1 \% \text { of total } \\
\text { population ( } 2015 \text { est.) }\end{array}$ & $\begin{array}{l}64.8 \% \text { of total population } \\
\text { ( } 2015 \text { est.) }\end{array}$ \\
\hline $\begin{array}{l}\text { Literacy Rate (Over age } 15 \\
\text { that can read and write) }\end{array}$ & $73.8 \%$ (2015 est.) & $59.6 \%$ (2015 est.) & $94.4 \%$ (2015 est.) \\
\hline OECD Member & No & No & No \\
\hline United Nations Member & Yes & Yes & Yes \\
\hline Security Council Member & No & No & No \\
\hline Unemployment Rate & $12.2 \%$ (2017 est.) & $13.4 \%$ (2017 est.) & $27.6 \%$ (2017 est.) \\
\hline GINI Index & $27.20(2018)$ & $22.40(2018)$ & $35.10(2018)$ \\
\hline
\end{tabular}

Table 2 Country Data Egypt, Nigeria, and South Africa ${ }^{5}$

${ }^{5}$ Data compiled from Index Mundi, Country Facts Find-the-Data, Global Innovation Index, and Basel Convention Website 
There are major statistics where the three countries differ including, but not limited to population size, and literacy rates. What's more, there are measures that are almost identical. One of the major differences to note is that Nigeria houses a larger population than Egypt at roughly 177,475,986 inhabitants while Egypt has a population of $89,579,670$ and South Africa has a population of 54,300,704. With so many denizens, and high urbanization rates, the amount of used electronics should run in tandem both in use and obsolescence. With larger numbers of millennials seeking new technologies products are thrown away at higher rates contributing to higher amounts of e-waste. However, I intend to analyze the strength of government regulation of waste and sufficient recycling programs which can be used to counter the rising obsolescence rates of electronic devices and equipment. This will begin to answer the query: why don't existing laws directly translate into the elimination of the e-waste problem? The slight gap in the unemployment rate between the two countries could imply that those not working under government regulation are involved in some fashion with the informal sector, which is often linked to scrapping materials in e-waste sites and that there may be a lack of jobs for the able-bodied population.

The GINI Index "measures the extent to which the distribution of income (or, in some cases, consumption expenditure) among individuals or households within an economy deviates from a perfectly equal distribution” (The World Bank Group, 2016). It is a vital tool for understanding how e-waste plays into the socio-economic realm of consumer society. Basically, the GINI Index helps define the spectrum of rich and poor within a country with values closest to 0 representing more equality and figures closer to 100 representing inequality. Theoretically, those with higher incomes can afford new 
technologies and the less affluent have to rely on secondhand goods which are often unserviceable. E-waste provides readier access to a much sought after commodity. Poverty is often synonymous with unemployment or a lack of a strong workforce which could also mean that there is a lack of proper training of the current labor force to conduct sufficient and efficient recycling techniques to decrease the amount of e-waste in a country.

The analysis in this study will explore a more extensive list of comparison variables. The simplified table above serves as a general framing of the demographics, and substantiates Egypt, Nigeria, and South Africa as viable units of study. The data available on these three countries is replete compared to other nations in close proximity like Algeria, Libya, Cameroon, and Zimbabwe. Ghana does have a substantial e-waste problem and a plethora of assessments have been conducted to investigate its e-waste concerns. The striking commonalities between Egypt, Nigeria, and South Africa, as well as the differences show that there is a deeper reason as to why e-waste dumping is rampant and uncontrolled.

By the end of this thesis, I will have attempted to answer the following questions: Why does Africa have such a prevalent e-waste problem; and what structures are emerging to regulate the growth of the e-waste industry in African countries? This will compel a broader discussion based on domestic e-waste generation, international trade, and the role that the current political and economic state plays in regulating waste and employment. This study will add another level of analysis to the literature surrounding the Pollution Havens Hypothesis and Race to the Bottom Theory looking at the nature of 
cooperation and competition within importing countries. The tenets of each theory will be used in conversation with each other in further discussion.

With 54 individual countries and one member-state of the African Union, the Western Sahara, Africa is the second most populous continent behind Asia. With obsolescence rates increasing with the rate of globalization, it is not surprising to see that e-waste mirrors this growth. The top three African countries with the highest e-waste generation in absolute quantities are Egypt (0.37 Mt), South Africa (0.35 Mt) and Nigeria (0.22 Mt) (Baldé, Wang, Kuehr, \& Huisman, 2015, p. 38). The Step Initiative, of the United Nations University, estimates that Egypt and Nigeria generated 373 metric kilotons and 219 metric kilotons of e-waste in 2014. On a smaller scale, Egypt and Nigeria generated 4.3 kilograms per inhabitant and 1.3 kilograms per inhabitant respectively. South Africa generated 346 metric kilotons of e-waste in 2014 and 6.6 kilograms per inhabitant.

It will be a much more strenuous task to create a map that shows the amount of ewaste imported from other countries per annum. Rough estimates can be made from various reporting mediums, but the overall figure is clouded by large quantities of ewaste being labelled and imported as charitable goods and donations or the shipments of e-waste that are not recorded at all.

Urbanization, ratio of informal to formal economy, lack of technical capacity and infrastructure, violation of international law including illegal trade practices, and lack of government will and cooperation through partnerships, initiatives, and projects all influence the continued growth of the e-waste tragedy Africa. As a point of comparison, many states in the United States of America have passed laws to ban electronics from 
being placed in landfills; in addition to this restriction these laws may stipulate that "manufacturers purchase recycled electronics under a formula based on the weight of the products sold" (Kambic, 2016). In a little over a decade "a total of 28 states and the District of Columbia have passed e-waste recycling laws" (Bennett, 2015). The problem with the handful of states without proper e-waste legislation is that the leftover electronics are then exported to developing countries through inconspicuous methods. It's not uncommon for companies to coordinate with exporters to ship junk overseas (Schmidt, 2006, p. A234). Often times this problem is intensified by the recipient nation's lack of government control or will.

Scholars, journalists, international organizations, and nongovernmental organizations alike all recognize that the above mentioned reasons contribute to the negative impact of e-waste. Therefore, I will undertake an analysis of e-waste in Egypt, Nigeria, and South Africa hoping to provide within country specificities and larger generalizations about the state of e-waste across the continent. Baldé et al. (2015) provides a straightforward, and succinct starting point to undertake an investigation of Africa proclaiming,

On the [African] continent, the e-waste challenge is on the political agenda the past couple of years, but there is generally a lack of e-waste management infrastructure, which is reflected by the absence of e-waste management laws. Here most of the generated e-waste is either stored in households, treated or dumped, according to the informal treatment sector. (p. 38)

In short, e-waste generation per capita can approximate the e-waste problem more broadly. It is the intent of this paper to develop this argument, support it with evidence from three case studies of Egypt, Nigeria, and South Africa, and provide a stronger, more feasible option for controlling the e-waste industry. 
By approaching the e-waste problem in Egypt, Nigeria, and South Africa as multilayered, I take Baldé et al. (2015) even further and argue that education, urbanization, a combination of lax import and strict export structures, illegal and unregulated trade, and lack of technical capacity and sound recycling infrastructures will be the factors with stronger association to the amount of e-waste generated in Egypt, Nigeria, and South Africa. Out of all of these variables, I would argue that the unregulated trade market poses the biggest threat to controlling this pandemic, as gross amounts of e-waste are brought into the developing world, more so than the actual production of e-waste within each country itself.

Furthermore, a handful of other factors play a more secondary role in the proliferation of e-waste; these include but are not limited to GDP per capita, unemployment rates, amount of people working in the informal sector, and the a nation's participation in or lack thereof in partnerships with international bodies or larger sustainability initiatives. It remains to be seen whether the last factor will become a more influential force as e-waste gains stock in the international agenda. My specific research question is: "What are the primary and secondary factors that influence the proliferation of e-waste dumping in developing countries? Additionally, it is my intent to show that recent practices at the local and national level have started this process. By the end, it is my intent to propose some sort of practical policy solution that incorporates NGOs, SMEs, recycling companies, and the governments of the states that suffer from the consequences of e-waste in light of its capacity to create job opportunities for those in the Global South. 
Egypt, Nigeria, and South Africa are the three most economically affluent countries in Africa with the potential to house a robust e-waste industry. However, each provides a distinct environment for such a nationwide practice to happen. Egypt has a growing number of youth initiatives and businesses that can cater to the MENA region as a whole. Nigeria, is Africa's richest country, but South Africa is on its tail. Nigeria also has militant group presence in its oil regions. This negatively affects market productivity. E-waste is a potential economy booster in a country like Nigeria if properly handled by both the government and a strong network of SMEs. South Africa has the most expansive coastline out of the three chosen nations in this study. Additionally, South Africa manages to export more of its e-waste than it recycles within its boundaries. This pattern is part and parcel of larger problems with waste management and recycling in South Africa. Local value chains are underdeveloped. Fortunately the innovative efforts of think tanks and various research and scientific councils are raising awareness of the opportunity for job development. The "[e-waste] sector generates around 25 jobs per 1000 tons of handled e-waste" (Moyo, 2017).

There is some credence to potentially analyzing the e-waste problem plaguing smaller countries in Africa. However, due to a dearth of qualitative and quantitative information the more fruitful research will emerge from the case studies of Egypt, Nigeria, and South Africa. All have a hidden potential in sparking a successful e-waste industry. 


\section{Chapter 4 Methodology}

This qualitative case study investigation will clarify the causal mechanisms at play exacerbating the e-waste problem within the countries of Egypt, Nigeria, and South Africa. I will explain the nature of the e-waste problem in Egypt, Nigeria, and South Africa by citing key figures and giving a general outline of each nation that incorporates an overview synopsis of each country and major proliferating factors addressed in the literature review. Following these introductory remarks, a description of enterprises and organizations that treat the e-waste problem will be included. This will be two fold in that there will be information collected on the structure of businesses local to the area and to the country as well as international corporations.

In order to understand the role that formal programs play in controlling the ewaste problem, I will look at the objectives of these enterprises from multiple data sources, namely company websites, using the framework of CSR. Additional data will be gathered from the internet on websites that are either linked with the companies in some capacity or have written articles and reviews about the company's work in regards to ewaste management. Most of the information collected will come from businesses working in major dumpsite areas and cities in each respective country. Testimonies and reports from these businesses will also be included to help defend my argument about ewaste and pollution havens. For each business, or corporation I will provide the types of services and major events that these enterprise conduct in relation to recycling, scrapping, collection, and resale. I will identify key patterns that emerge from the various entities and also note individual differences in Egypt, Nigeria, and South Africa in order to link 
the data and build an explanation that will ultimately support theories highlighted earlier in this investigation; or serve to devise a new theory about trade waste.

Furthermore, I will collect narratives from business owners, local residents, and volunteers that discuss the workings of each business in relation to the e-waste problem as a whole and specifically within the region in which they work. I will also give a framework of the role that SMEs and nonprofit organizations play in the e-waste industry and how in the coming decades, these structures could help to control the e-waste problem. If applicable, I will also look into videos on the internet from websites such as YouTube, and websites based out of the respective countries in this analysis. These could include instructional videos, photo and clip montages, interviews, and recordings of events. I will then assess how each enterprise understands the way that CSR, economic incentives, and environmental theories of justice interweave into their e-waste management strategies. 


\section{Chapter 5 Case Studies}

Egypt

Egypt's location on the Mediterranean and Red Sea allows for easy cargo access.

The most highly populated areas, Alexandria and Cairo, lay on and close to the Mediterranean Sea respectively. Along with trade accessibility, Egypt is one of the leading producers of e-waste in Africa. Its sizable population has a large number of young adults pining for new technology, which sparks the obsolescence of electronics. Its purchasing power, though relatively high (around 1.1 trillion est. 2016) still results in the acquisition of cheaper electronics (Duff, 2017). The quality of these cheaper electronics leads to faster deterioration and therefore higher amounts of e-waste (Duff, 2017). To summarize,

Although the amount of e-waste in the country is high, the number of formal ewaste recyclers is low and these recyclers operate on a small scale. There is no formal collection system of e-waste, no specific regulation or financing mechanism and the involvement of the producers is low compared to Europe. Most of the e-waste is therefore collected and treated through informal channels, with poor health and safety conditions, and high environmental impact. (Sustainable Recycling Industries, 2015)

Egyptian legislation tends to focus on policies that impact production and not post factum management as soon as electronic products become obsolete.

Egypt houses one of the Basel Convention Regional Centers. Currently, it serves 22 Arab states in Africa and West Asia. Though not an SME, BCRC-Egypt is a nonprofit intergovernmental organization capable of employing administrative and consulting staff for major projects, trainings, and workshops.

Additionally, a needs assessment conducted by the Centre for Environment for the Arab Region and Europe (CEDARE), states that formal legislation in Egypt circles the 
issue of e-waste, but neglects to directly address e-waste in its own right. This group claims, "there is no overall integrated environmental policy regarding WEEE in Egypt, but the legal framework in Egypt includes restrictions on imports of WEEE and restrictions by virtue of commitments to international conventions, specifically the Basel Convention (CEDARE, 2011, p. 7-8). The Egyptian Environmental Affairs Agency is "a coordinating \& regulatory body mandated to set (in cooperation and coordination with the all the development sectors and other involved stockholders in the country) the environmental policies and national environmental action plan” (CESARE, 2011, p. 8). The EEAA is arguably one of it not the strong environmental regulation body in the country. It "also has the mandates to prepare draft environmental regulations based on strong rational from the development sectors. In addition it mandated with inspection roles which cover any violations to the environment law including improper management of WEEE” (CESARE, 2011, p. 8).

Egypt has an increasing demand for technology. The Association for Progressive Communications states,

Technology is playing an increasing role in the everyday lives of Egyptians. According to the latest studies, the number of internet users grew from 9.7 million in June 2008 to 13.5 million in June 2009 - an increase of $39.2 \% .1$ The number of mobile phone users has also grown significantly, from 32.7 million users in June 2008 to 48.3 million users in June 2009 - an increase of $47.7 \%$. (APC News, 2011)

It should follow that electronic goods readily cross Egyptian borders as this demand continues to increase as the population grows.

Attempts to create concrete environmental e-waste policy are emerging in Egypt through cooperative efforts with European countries like Switzerland. Switzerland 
provides funding in various development areas in Egypt. For the past 2 years, after conducting a needs assessment in 2011, Egypt and Switzerland found a way to tackle the e-waste problem and promote the efforts of small and medium enterprises in the "Sustainable Recycling Industries in Egypt" project. This project has three goals:

The first is to contribute to the promotion of policies and standards for the sustainable management of secondary resources. The second is to create local capacities for sustainable recycling industries, and the third is to provide cities across Egypt and other countries with access to experiences developed under the project. (World Resources Forum, 2016)

This two year project aimed to turn the dirty electronic waste industry into job and income opportunities. It aims to not only sustain Egypt's growing economy but also to develop and presence of responsibility, through financial, administrative, legal and technical support, the project encourages small and medium-sized Egyptian companies to develop a viable business by recycling electronic waste in a safe and environmentally friendly way (World Resources Forum, 2016).

What makes Egypt an interesting case study is its growing youth initiatives and the way that cooperative efforts within its borders in its most desolate areas are starting to slow the spread of the e-waste problem by attempting to formalize a discernibly informal e-waste sector. Furthermore, in March of 2016 "the Embassy of Switzerland signed with Egypt's Ministry of Communications and Information Technology the Sustainable Recycling Industries in Egypt agreement (SRI) to promote the recycling of electronic waste among Egyptian small and medium-sized enterprises (SME)" (Daily News Egypt, 2016). ITG, Recyclobekia, SpearInk, Spirit of Youth Association, Mobini and CID consulting constitute ambitious examples of local private sector enterprises working in e- 
waste management field (Tewfik and Shakra, 2013). Within this brief case study I will allude to a more comprehensive initiative with more formal mechanisms and education grounding its actions and a slum settlement, tenured and somewhat archaic in its methods of handling recycling and waste including electronics. I will also include a more in depth look at an assortment of companies that vary in size and product focus.

As previously mentioned, part of the story of waste management in Egypt starts in Cairo's slum settlement Manshiyat Nasser. It is located at the base of Mokattan hill which emerged during the mid-1970s. Roughly, " 85 per cent of [the waste] is sorted and recycled by the people there, and then sold on" (Daily Mail Reporter, 2011). The image below shows the accrual of waste in Manshiyat Nasser:

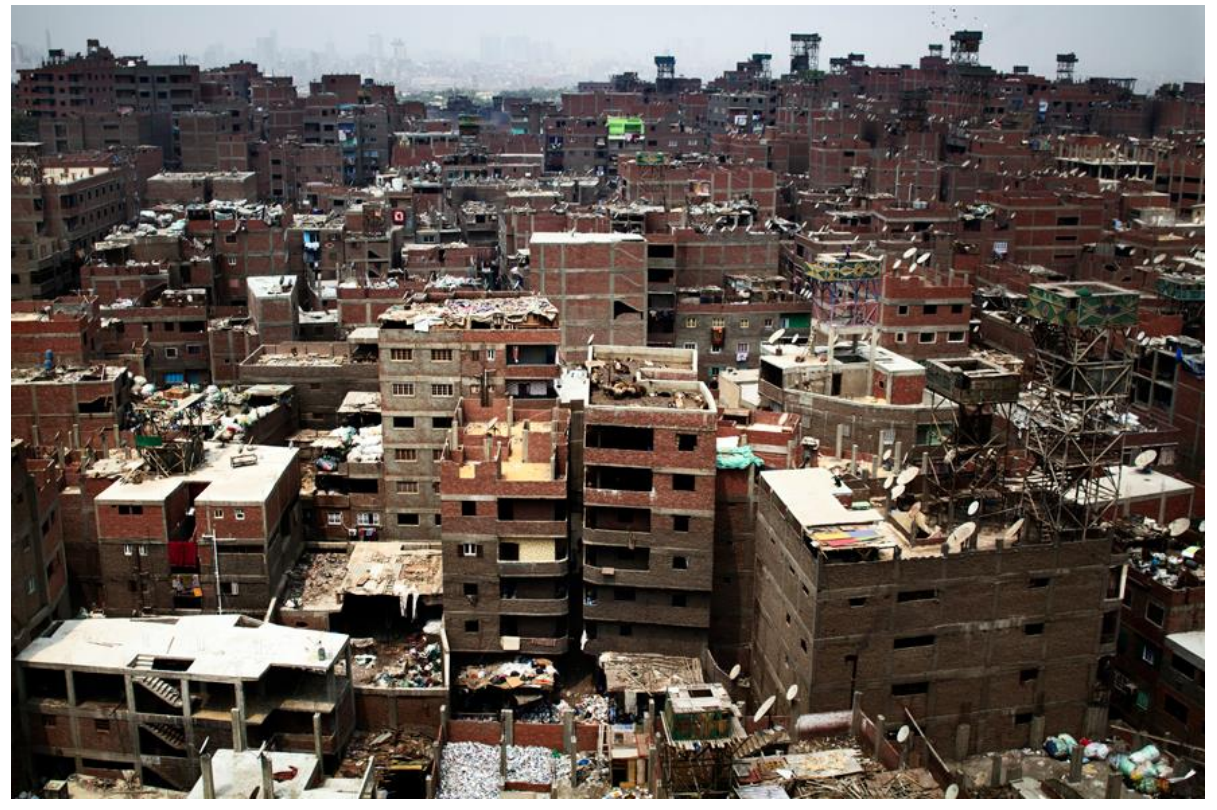

Figure 4 Manshiyat Nasser Cairo, Egypt (Quiros, 2014) ${ }^{6}$

\footnotetext{
${ }^{6}$ Quiros, M. (2014). Manshiyat Nasser Cairo, Egypt [digital image]. Retrieved from http://www.manelquiros.com/thegarbagecity/. Copyright 2014 by Manel Quiros
} 
Manshiyat Nasser is "[a] village...notable for having nearly every space of it covered in garbage, including the streets and rooftops of the settlement. These piles of garbage are the result of the Cairo Metropolitan Area having never established an efficient garbage collecting system (Atlas Obscura, n.d.)." Manshiyat Nasser houses an informal youth initiative powered by young girls. Here, the incentive of e-waste management is recognized and addressed as weekly endeavor. The girls work together with a teacher to repair non-working computers and attempt to sell individually rebuilt units around $\$ 300$ each at the local market in the ward. The income is allocated to the girls, warehouse facilities and the trainers. Leftover parts, and salvageable metals are then sent for recycling. Field researcher, Janine Wilkin, adds more context to this description of Manshiyat Nasser and a growing youth initiative. She adds on her experience in Manshiyat Nasser,

I was disheartened when I tried to learn more about this program, as I could not locate any more information. But the situation of trash in Cairo is a huge infrastructural barrier to the development of the nation, as there is not even a government led waste-pick-up program through the country. (Wilkin, 2013)

More field work needs to be conducted to truly grasp the severity of the e-waste problem in Egypt and to track the success of this youth initiative.

Other markets that can be considered e-waste hubs in Cairo are Shoubra El Khema Market-Manshiet Abdel Moniem Riad, El Warrak Market in the Imbaba district, El Kollaly Market, El Imam El Shafies Public Market, and El-Matareya Market. CEDARE found that "the markets of e-waste have grown in Egypt organically and without prior planning or government intervention to mitigate impacts" (2011, p. 10). These markets "are mostly in the form of dispersed workshops and informal vendors 
densely integrated in the urban fabric of poorer areas of Greater Cairo" (CEDARE, 2011, p. 10). Along with the e-waste markets, the larger refurbishment industry in Egypt is also located in less affluent districts.

Egypt is replete with sizable companies and smaller businesses that deal with electronic waste in some capacity, including recycling, dismantling, scrapping. One key private sector enterprise is the Egyptian Electronics Recycling Company (EERC) which aids individuals, companies, and governments in efficiently recycling electronic waste. Per the EERC webpage the company recognizes that, with "the Electronic Waste Recycling Act No.9 of 2009, certain portions of the electronic waste stream are defined and the systems to recycle them will be administratively regulated beyond the universal waste rules that apply to material handling" (Egyptian Electronics Recycling Company, 2017).

Arguably, the most well-known e-waste focused SME in Egypt is Recyclobekia. It was established in 2011 and it serves the Middle East and the MENA region with its headquarters in Cairo, Egypt. The business structure of Recyclobekia follows a fourpronged recycling process: collecting, sorting and dismantling, packaging and refining. Recyclobekia takes electronics from a range of entities organizations, companies, workshops, individuals. Its employees are well equipped with the knowledge needed to perform the sorting and dismantling as well as the packaging. In addition, Recyclobekia also provides in depth data destruction services to protect users from identity theft and larger entities from having confidential information stolen.

Along with the employees of Recyclobekia it is appealing to the younger generation and the influence they can have on their environment. From the Recyclobekia 
YouTube feed I found a video titled, Recyclobekia in Alex Bibliotheca. In the video we observe an arts and craft set up where children are given the opportunity to find creative ways to make art out of parts that are more than likely not salvageable (Recyclobekia, 2017). This helps instill a values system that adopts responsibility at its core. Children become aware that solely because a computer, phone, laptop doesn't work or isn't the most recent model, doesn't mean it can't have some reuse. It also teaches the upcoming generation to care, to be excited about the idea of recycling and to be active not passive in their involvement. Recyclobekia has adopted a vision of building a recycling army, and youth are only one small part.

Recyclobekia hosted an event at Hayah International Academy in March of 2014 which serves as another example of the initiative that Recyclobekia is taking to engage with youth and their role in combating the growing e-waste problem (Recyclobekia, 2014). This event focused on not only teaching kids about the detrimental effects of poor waste management but also how they can take simple steps to recycle e-waste in their local communities. There were flyers as well as interactive events for the children. To make the event fun they also provided a prize wheel for select electronic devices. Additionally, the youth were given a chance to write their thoughts on the entire experience on a comment board.

The International Technology Group (ITG), established in 2010, is another SME that centers its mission on recycling and collecting obsolete electronics such as laptops printers and cell phones. This SME is less publicized than Recyclobekia, but has invested in a relatively new experimental phase of chemical separation during the recycling process to increase efficiency in the recycling of electronic waste. Manager Ahmed 
Salem avows that these experiments "have been showing positive results and that the factory is expecting to reach economically feasible methods" (El-Din, 2016). The fact that smaller companies are attempting to invest their resources in innovative methods also speaks to the seemingly lackadaisical efforts of many international companies.

SpearInk is another local enterprise that has an office in Alexandria, with its main headquarters in Dubai. It was founded in 2006 after one entrepreneur, Essam Hashem, discovered that businesses and entrepreneurs had not capitalized on the opportunity surrounding ink cartridges. In a 2015 interview with SpearInk founder Essam Hashem Rachel Williamson of Wamda inquires as to how Hashem would get other businesses to respond to SpearInk's mission of e-waste recycling. Hashem avows,

My business is based on cultural change around waste disposal, so I needed to put a lot of effort into awareness campaigns and waste collection campaigns. For example, we have the Green Sharm and Green Aswan initiatives for electronic waste collection, collaborating with the governorate and Ministry of Environment. It was a kind of corporate social responsibility, to raise the awareness about hazardous e-waste, and to each governmental organizations and NGOs how to eliminate it. (Williamson, 2015)

By the end of the 2015 interview conducted by Rachel Williamson of WAMDA, Hashem concludes "the real treasure, which is more than any income, is the enjoyment of turning trash into something useful" (Williamson, 2015). Now, Hashem has SpearkInk franchises all over the Middle East in Egypt, Syria, Jordan and Lebanon. One of its main goals is to promote recycling and refurbishing all over Middle East and North Africa (MENA) region.

In one 7 minute video montage on YouTube, SpearInk illustrates the entire process of refurbishing inkjet cartridges and refilling ink machines (SpearkInk Company, 
2014). The video begins with an image of collection bins and follows through key components of SpearInk from the machines that checks and refills ink color as well as the cleaning of old cartridges and maintenance. The entire operation is streamlined. SpearInk manages to save "around 15 tons of plastic, 2.5 tons in aluminum and toner powder, five tons of rubber and metals, and 4.5 tons of polyurethane and metals," moreover it "refills around 4000 cartridges per month" (The Recycler, 2015).

Although the list of successful SMEs in Egypt continues to grow there are recycling centers that lack the means to become a substantial enterprise. One such example was a treatment facility established in 2005 known as the Nasreya Hazardous Waste Treatment Centre in Alexandria, Egypt. Initially, it was founded under the Hazardous Waste Management Project (HWMP) in Alexandria and has recently joined hands with Korean International Cooperation Agency (KOICA) and Alexandria University to recycle fluorescent light tubes and plastic respectively. In light of this positive cooperation the center has not been able to gain extensive ground as an enterprise due to its limited connections with major stakeholders and its inability to create an incentive scheme...to motivate the private, public, and civic sector to send waste to the recycling facility (CEDARE, 2011, p. 14). The private sector, seeks monetary compensation for the WEEE. Luckily, the KOICA has continued to work with the Nasreya center and hopes to convince private sector enterprises to join in the initiative recycling initiatives.

Phone companies both large in scale and more localized have their hands working within the e-waste problem. For example Nokia, Mobinil, Vodafone Egypt all recognize and act upon their role in e-waste proliferation and its subsequent management. Nokia's 
CSR rests in its mantra of "[taking] sustainability into account along the entire life cycle of products, services and operation" that is, it's "approach is to consider recycling already before devices are made" (CEDARE, 2011, p. 18). Back in 2009, Nokia launched the Nokia Care's Take Back and Recycling Scheme in Egypt. This was part of a larger catalyst of recycling channels to cover many countries in the Arab region. Aside from its physical care point locations, Nokia also makes an effort to provide educational campaigns, awareness raising campaigns and recycling activation in the UAE, Lebanon, Egypt and Pakistan (CEDARE, 2011, p. 18). By 2017, The 2018 People and Planet Report states that as of 2017 Nokia has managed to extend its sales reach and cooperative efforts to over 130 countries (Nokia, 2018, p. 36).

Nigeria

Unbelievably, Nigeria does not have a single legally licensed landfill despite having a population of 115 million and being a popular e-waste dumping ground (Metcalfe, 2011). The EU and China dump e-waste into Nigeria at alarming rates. In one BBC recorded interview, BCCC Africa official Percy Onianwa states 77\% of Nigerian ewaste imports are coming from the EU, and 15\% come from China even though the latter is normally viewed as one of the main dumping grounds for e-waste (BBC World Service, 2018). With a dearth of licensed landfills, the number of dumping sites continues to multiply. In a presentation by Engr. Adebola R. Shabi, the General Manager of the Lagos State Environmental Protection Agency it is noted, about 50 to $80 \%$ of the recycling in Lagos, Nigeria alone is done through informal methods (Shabi, n.d., p. 11). According to Nigerian officials, a number of internal factors have contributed to the 
problem. Some of these factors include a "growing market for affordable computers, the local culture of "patching things up," the fact that old computers can be imported duty free, and poor waste management have led to the increase in toxic electronic waste" (BioRes, 2008). If the ICT market is ballooning at such an alarming pace, this necessitates the creation of a robust network of SMEs that incorporate ETJ and CSR.

Note again, that Nigeria has ratified the Basel Convention and signed the Bamako convention lending some accountability to international law. Conjointly, legislation exists that should prohibit the simple sending of old PCs to be dumped - but the problem is that Nigeria's booming second-hand computer industry gives ample scope for computer waste to be brought in. (Carney, 2006). The "Harmful Waste (Special Criminal Provisions) Act, 1988, prohibit[s] the carrying, depositing and dumping of harmful waste on any land, territorial waters" (Shabi, n.d., p. 17). Moreover, Nigeria participates in different initiatives. One such initiative is the " [Memorandum of Understanding] MOU signed between NESREA, Standard Organization of Nigeria, Consumer Protection Council and Alaba international, another being the "Market Amalgamated Traders Associated to fight e-waste and privacy" (Shabi, n.d., p. 17) .

In 2010, an Electronic Waste Bill [was] proposed to the National Assembly by the National Environmental Standards and Regulations Enforcement Agency, NESREA and the Federal Ministry of Environment (Olubunmi, 2010). Now, roughly a decade later, this proposed legislation is yet to pass, and has seemingly disappeared from the docket of potential legal frameworks that can help to manage the growing e-waste problem in Nigeria. Luckily, 
There are...some government organizations saddled with the direct or indirect regulation and management of E-Waste in Nigeria, namely: the Federal Environmental Protection Agency (FEPA), the National Environmental Standards and Regulations Enforcement Agency (NESREA), the National Emergency Management Agency (NEMA), the National Space Research and Development Agency (NASRDA), and the Nigeria Customs Service (NCS). (Olutoyin, 2017, p. 14)

In brief, Nigeria attempts to stay in accordance with a number of laws, international acts, and regulations from national agencies as well as non-legislative, non-governmental agreements. But, this attempt is squandered by the lack of absolutely exhaustive legislation and firm enforcement protocols. As years have passed the number of regulations and bodies constructed to deal with waste has increased and the ideal outcome would be for strict observance of these established rules.

As highlighted in the aforementioned section describing the tenets of the Basel Convention, Nigeria houses a BCRC. The Basel Convention Coordination Centre for the African Region in Nigeria is located at the University of Ibadan which is roughly 70 miles northeast of the major port city of Lagos. Like similar BCRCs around the globe:

The center plays a key role in building the capacity of the African countries to implement the Basel Convention and its amendments, and to enhance their knowledge of chemicals and hazardous wastes issues and to address their lack of inventories on waste generation and other infrastructural deficiencies which are expressed in the priority needs of the countries. The center receives financial assistance from the Federal Government of Nigeria, and the Basel Convention Trust fund. Potential future sources of funding include revenue from the services provided, fees and earned interest charged by the center. (Basel Convention, 2017)

Even with these larger objectives, funding, and general implementary power of the Basel Convention, there is an overabundance of illegal trade of hazardous waste in Nigeria. The Nigerian government needs to properly enforce the Basel Convention. If the proposed ewaste bill ever comes to pass, Nigeria has ample opportunity to fashion a robust, ethical, 
and politically sound e-waste industry that attempts to bring together key stakeholders, reduces environmental degradation, and decreases health hazards. Even though cities like Lagos house e-waste dumpsites and have become "pollution havens" the growing e-waste industry, if formalized, can challenge RTB theory by improving the standards of workplace safety, product quality, and fair pay.

Alaba Market, Westminster Market, Lawanson Market, Ikeja Computer Village, Ojota Scrap Market, Solous Dumpsite, and Olusosun Dumpsite are the seven major ewaste and garbage dump-sites in the greater Lagos area. There are smaller to medium size auxiliary locations in Lagos and other major cities in Nigeria such as Rivers State and Kano. Even with this seemingly coordinated location matrix of e-waste markets in Lagos, the cooperation between the sites has been minimal for decades. For years the lack of substantial networking between the markets, or the businesses within is part and parcel of the disproportionate size of the informal sector to the formal sector. It is disjointed at best and falls into a compartmentalized web of informal and formal practice. However, one existing process of e-waste importing does show some semblance of organization and cooperative change. It begins as such: IT importers, who also act as brokers in the Lagos seaports often purchase cargo containers by weight and not by the value of the goods inside. After determining the quality of the cargo, it is then distributed to local e-waste markets such as the Ikeja Computer Village and the Alaba International Market (Petricca, 2017). The majority of these markets house an overpopulation of youth scavengers and scrappers as well as makeshift retail outlet stands. These markets, however, will no longer have to bare the entire burden of refurbishing and dismantling obsolete electronic equipment. 
The Computer and Allied Product Dealer Association of Nigeria (CAPDAN) coordinates the affairs of the IT industry. In recent negotiations with the Lagos government, CAPDAN and Lagos state reached a concession agreement that will allow for the "relocation [of] businesses in Ikeja Computer Village, the nation's largest technology market cluster, to the proposed ICT Park at Katangowa in Lagos" (Akinola, 2018). This ICT Park is one major milestone for e-waste management in Nigeria and has the potential to increase the role of SMEs throughout the country. The vision involves a holistic level of organizing that utilizes all facets of society from squatters, to roadside vendors, to tenured businesses. Moreover, the Lagos State government is investing money and resources into making Lagos a technology driven Smart City. Here we find a real world situation that is implementing the proposed solution by Chintan in India highlight in Chapter 1.

Ahmed Ojukutu, recent President of CAPDAN, stated in a Technology Times interview, "what is paramount to us as an association is everybody in the present day Computer Village, so that even that woman that is squatting with somebody and the man with a small table will be factored in into the movement (Akinola, 2018). A Smart City, can positively impact all facets of society from the scavengers to the governing bodies. Economically it will provide a space for stable employment and politically it will be a major hub for international trade and negotiation.

Additionally, a heavily regulated Smart City will decrease the dangers of informal recycling, especially the health and environmental hazards. This can be accomplished through green technology and well-constructed infrastructure. Overall, the Lagos State and CAPDAN are providing a space for SMEs to thrive and boost national development. 
It will also be a major hub for roughly 3000 traders, registered and unregistered. This will present a double edge sword in that this massive business metropolis will be heavily regulated. It remains to be seen how crime levels and environmental dangers are monitored. There are doubts as to the potential success of such an endeavor, "as the city of Lagos is too large to easily bring the collected materials to a central recycling site (Manhart et al., 2011, p. XII).

As aforementioned, Hewlett Packard has incorporated CSR into its environmental initiatives. It is only within the last decade that its influence has spread to multiple African nations, including Nigeria. In an interview with HP's environmental take-back compliance manager Kirstie McIntyre "she was asked why the initiative was not starting in countries with bigger e-waste problems, such as Nigeria” (Amorim, 2007). Since the initiative has focused on countries like Kenya, Morocco, and Tunisia her response, though not alarming, highlights what measurements corporations take to determine where they implement CSR. McIntyre stated, "the initiative was starting in countries with a higher gross domestic product, which have higher electronic purchase levels and therefore urgently need structures in place to deal with potential e-waste increases" (Amorim, 2007). The irony here is that Nigeria houses the largest economy in Africa.

One in house enterprise starting to break through the e-waste problem is E-Terra Technologies Ltd. E-Terra "is a young, pioneering e-waste management company that is poised to keep Nigeria evergreen and sustainable, in response to new technological challenges to our rich vibrant ecosystem that includes the world's largest continental mangrove swamp" (E-Terra Technologies, 2016). In a February 2018 E-Terra article by 4 methods are highlighted for tackling the e-waste problem in Nigeria. E-Terra 
recognizes that this is a worldwide pandemic that has managed to spread rampantly within Nigeria borders. The key points are as follows: show that cash can be made from trash, upgrade the informal sector, synergize regulatory bodies and enact e-waste collection policies, and enlighten the people on the dangers of e-waste and how to curb them (E-Terra Technologies, 2018).

In all of the above listed practices we find a strong link to the tenets of CSR. The first clearly states, that e-waste has value and can affect the Nigerian economy positively, whether through salvaging key metals like copper or utilizing other pieces of equipment and making it into seemingly unexpected enterprises like jewelry. Upgrading the informal sector speaks to the recognition of the harmful nature of e-waste. Informal processes more often than not elect to use burning as the major mechanism of handling e-waste. One of E-terra's major focuses is to press for a more qualified and adept informal sector where "stricter measures must be put in place to ensure that the extraction of valuables and the recycling of e-waste follows all regulations that ensures the safety first of those handling the materials and then the general public" (E-Terra Technologies, 2018). They also acknowledge "improper electronic waste disposal is not only harmful to man and the environment, it also exposes organizations and individuals to identity and intellectual property theft" (E-Terra Technologies, 2016).

The Initiates PLC is another SME that houses an e-waste processing facility. This SME has a variety of services that keep in line with HSE standards and Nigerian government regulations. The Initiates PLC has the ability to process household appliances, communication devices like laptops, entertainment electronics, lighting equipment, electrical tools, and sports equipment such as electronic training devices. This 
SME promotes a high standard of CSR in its daily work from the destruction of data to protect businesses from data leakage to the recovery of mercury using Balcon Bulb Crushing and Mercury Recovery equipment. On the Initiates PLC website it states, "the glass and the mercury are collected separately without any release into the environment as the system is a closed loop recovery unit with HEPA filter that carries out filtration of the mercury vapor" (The Initiates PLC, 2018).

Nigeria continues to make an effort to change the tide of the e-waste problem within its borders. According to the National Environmental Standards and Regulations Enforcement Agency (NESREA) Nigeria's actions are operating under the framework of national and international partnering. NESREA itself is working alongside the:

Nigeria Customs Service and all the members of the National Toxic Waste Dump Watch committee on the illegal shipment of WEEE" while internationally, there are collaborative efforts with International Network for Environmental Compliance and Enforcement (INECE), Seaport Environmental Security Network (SESN), International Criminal Police Organization (INTERPOL), United States EPA, UK EA, Germany, VROM, IMPEL TFS, EPAT and other sister Agencies. (Amachree, 2013, p. 20)

One of the key methods employed by NESREA is repatriation of goods. Below is a simplified chart of NESREA's international repatriation of e-waste.

\begin{tabular}{|c|c|c|}
\hline \multicolumn{2}{|c|}{ E-waste Repatriated by NESREA from 2010-2013 } \\
\hline Country of Origin & Year & Type of Container \& Amount \\
\hline Austria & 2010 & UESEA 463595-0 (1) \\
\hline Germany & 2010 & $7 x 40 f t$ and 2x20ft trucks (2) \\
\hline $\begin{array}{c}\text { United States of } \\
\text { America }\end{array}$ & 2010 & 4x40ft ZCSU 82397694-5, ZCSU 82392024-5, ZCSU 81973444-5 \\
\hline United Kingdom & 2010 & GCNU 463667-3, GCNU 463871-6 (2) \\
\hline Malaysia & 2012 & TGHU 353945-7 (1) \\
\hline
\end{tabular}




\begin{tabular}{|c|c|c|} 
Singapore & 2012 & TGHU 736337-1 (1) \\
\hline Korea & 2012 & 40ft PCIU 999156-0 (1) \\
\hline Japan & 2012 & 1x40ft MOAU 772496-3 and 1x20ft UNIU 205536-0 (2) \\
\hline United Kingdom & 2013 & 2x40ft ECMU 987085-8 and ECMU 989451--0 (2) \\
\hline Belgium & 2013 & 3 Trucks \\
\hline
\end{tabular}

Table 3 E-waste Repatriated by NESREA from 2010-20137

The above table shows some of the successful work NESREA has done to control the illegal waste trade. Similarly, this repatriation shows that cities like Lagos have become pollution havens. NESREA is one organization with enforcement power; it can in practice limit the use of technology and equipment that undermines environmental quality (Okukpon, 2015, p. 241). If the illegal waste trade is faced with greater regulation the idea of pollution havens may diminish and reformulate into a less "dirty" industry. Ridding the world of waste is superfluous, but changing the nature of how waste is framed in the social and political world starts with how obsolete products can be salvaged and how those guilty of illegal dumping can be held accountable.

\section{South Africa}

The second largest economy in Africa belongs to South Africa. Its location, not necessarily in close proximity to larger developed nations, gains trade value from the large coast line and easy access for cargo. Legislatively, there are a handful of provisions and acts on the whole that frame waste legislation on the whole in South Africa. These should easily be applied to the e-waste industry. Firstly, "the South African Constitution

\footnotetext{
7 (Amachree, 2013, p. 22)
} 
establishes basic environmental rights including the right to an environment that is not detrimental to one's health; just administrative action and access to information. These form the basis for the country's environmental and waste legislation" (Ecroignard, 2006, p. 47). Secondly, the German Corporation for International Cooperation GmbH (GIZ) acknowledges that "the e-waste handling and recycling landscape is highly fragmented and largely unprofitable" (Watson, 2014). This fragmentation and unprofitability stems from an attitude of apathy; e-waste is not seen as an immediate threat. This apathy is apparent along the entire spectrum in South African society from government officials to individual citizens.

Alongside the South African Constitution, is the 1998 National Environmental Management Act (NEMA). According to EWasa, "NEMA Waste Management is provided for in the Act with principles such as polluter pays and cradle to grave" (Ecroignard, 2006, p. 47). The "NEMA refers to avoidance or minimization and remediation of pollution, including waste reduction, re-use, recycling and proper waste disposal" (Ecroignard, 2006, p. 47). This act helps to promote and maintain quality environmental management practices from micro to macro level interaction; i.e. the individual, businesses, and governmental bodies.

At its heart, the Occupational Health and Safety Act of 1993 seeks to protect the basic rights and overall health of workers. What this act mandates is safety in the workplace environment, especially in areas that have heavy machinery like industrial plants. However, Keith Anderson of the E-Waste Association of South Africa (EWasa) attests that, "the current legislation has gaps" (Mhlanga, 2018). Unfortunately, the OHSA of 1993, fails to cover the informal sector, even though injury and illness are 
rampant in South African e-waste dumpsites. This lends credence to formalizing the ewaste industry in South Africa so worker's rights are addressed.

Most of South Africa's e-waste management is regulated by the National Environmental Management: Waste Act of 2008 and the National Waste Management Strategy of 2011. These acts include EPR measures for waste management (Okukpon, 2015, p. 167). The Consumer Protection Act (CPA) of 2008 works in tandem with the Waste Act of 2008 placing greater responsibility on the suppliers of goods. In brief, "under the CPA, the entities mentioned are to concern themselves with the proper disposal of the goods, components, etc. and must create collection points/recycling facilities for the return of such goods" (Okukpon, 2015, p. 167). Many manufacturers see these provisions as guidelines rather than rule of law, and the enforcement mechanism is weak.

In light of the obvious shortcomings, the waste recycling SMEs emerging in South Africa are intentionally incorporating the management strategies highlighted in the various South African waste management laws. As a result, it is imperative that SMEs work cooperatively with the South African government and continually adhere to the EPR measures stressed. Additionally, larger international companies, like Nokia, that are starting take back initiatives in South Africa need to engage proactively with the South African government and create environmentally friendly products limiting the negative impact of e-waste.

The Africa Institute, which is both a BCRC and a Stockholm Convention Regional Center (SCRC) located in Pretoria, South Africa serves a total of 23 English speaking African countries. This center focuses on environmentally sound management 
of hazardous waste and also advocates for the enactment of capacity building initiatives stressed by the Rotterdam Convention (Africa Institute, 2018).

EWasa is a larger non-profit organization in South Africa that "envisages an industry-led take back system with legislative requirements for producers, importers, and distributors to take back old and end-of-life products (Ecroignard, 2006, p. 49). This take back schema is part of a larger EPR design. As an association, EWasa is comprised of EEE vendors, distributers, manufactures, recyclers as well as those directly involved with e-waste such as dismantlers and refurbishers (Okukpon, 2015, p. 200). It endeavors to hold its members responsible for their products and to promote their general interests in the e-waste industry. EWasa tracks the practice of roughly 100 recycling centers around South Africa and strives to make e-waste an economically viable industry through regulated advanced recycling fees charged from top to bottom; i.e. from producers to consumers. The majority of the roughly 100 recycling centers are located along the coast and in major metropolitan areas. It comes as no surprise that Cape Town and Durban house a significant number of e-waste organizations and recycling centers. Port Elizabeth and the heavily populated capital, Johannesburg house a dense concentration of recycling centers as well.

In 2009, Amie Williams, a noted filmmaker for nongovernmental organizations and international development organizations, travelled to South Africa to take a closer look at the groundbreaking work of local activists. She compiled a brief informational YouTube video documenting the nature of e-waste combattance by EWasa and a sister organization called The E-waste Alliance. She investigated the negative nature of informal recycling and salvaging and was able to see the positive effect e-waste SMEs 
have on employment rates. One gentleman, named Lwandile Jayiya, noted he knew nothing of computers but through being employed with Just PC has learned a lot (Williams, 2009). There is an unmistakable mantra within the EWasa organization that incorporates CSR and shuns the individuals that improperly dispose of electronics for valuable pieces of copper. During the interviews of organization leaders as well as employees we learn that e-waste is the fastest growing waste stream in South Africa. Susan Dittke, EWasa Project Coordinator, highlights the difference between the formalized methods of EWasa versus the activities in scrap yards. One section of the clip portrays a man smashing a potentially salvageable computer monitor for the copper coil inside. The lack of attention to the latter aspect of e-waste recycling is apparent in areas where monetary value is the highest (and often the only) concern.

Founded in 1992, Desco Electronics Recyclers out of Johannesburg is one of the larger SMEs in South Africa with roughly 13 certifications, licenses, and permits including membership of EWasa and the South African E-waste Alliance (SAEWA). Desco offers services to other SMEs in South Africa along with large corporations and helping out the general public. Some of the main services offered are "collection of electrical and electronic equipment/ waste from customer sites, buying and disposing of excess and redundant equipment, warehouse and computer room clear-outs, secure data and hardware destruction, including Certificate of Destruction" (Desco Electronics Recyclers, 2018). Desco is committed to offering a "socially responsible solution for ewaste and [gives] peace of mind ensuring that your business is contributing to reducing its carbon footprint, as well as recycling e-waste responsibly" (Desco Electronics Recyclers, 2018). The company also strives to be "a good steward of the environment, 
and will in all circumstances aspire to constantly emphasize awareness of the natural environment, whilst maintaining a level of proficiency which demonstrates bona fide leadership in all spheres of the environment" (Desco Electronics Recyclers, 2018).

Desco is one example of a SME that has ties to international corporations. As of 2014, Samsung has partnered with Makro and Desco to "educate consumers on erecycling and the disposing of electronic goods in an environmentally responsible manner" (Samsung Newsroom, 2014). One tangible way this mission is enacted is through the placement of Desco/Samsung recycle bins in front of major retail stores. The campaign that has emerged from this partnership is ongoing. Michelle Potgieter, Director of Corporate Marketing and Communications at Samsung Electronics SA is quoted in an article from Infrastructure News on this collaborative effort stating,

This campaign encourages the community to think about the environmental impact of their actions and the role they can play in bringing about positive change in their communities. We are proud to be associated with DESCO and Makro and look forward to making a difference to the environment with our partners. (Infrastructure News, 2014)

As long as companies, such as Samsung, not only recognize their role in the broader scheme of the e-waste industry, but also take the responsibility to partner with in house SMEs, the negative consequences of e-waste dumping can be controlled.

Another SME, located in Port Elizabeth that specializes in refurbishing, reselling, and recycling is E-waste Technologies Africa (EWT). For roughly two decades the founder of EWT, Enrico Vermaak has expanded his knowledge of the Information and Communication Technology industry. As such, the EWT list of services not only includes process flow, asset verification, and data sanitation, and data destruction but also 
continues to grow as the company partners with local SMEs and larger corporations. In turn, CSR is deeply embedded in EWT's mission and core values and the company strives to sponsor CSR through:

[Partnering] with non-profit organizations to re-use all...working IT equipment. This process alleviates some...onerous CSR by partnering with e-waste Technologies Africa's Managed e-Waste services. Our service ensures that the organizations being donated to have the appropriate facilities, i.e. power, security, trained teachers, ongoing support, Microsoft Registered Refurbisher licensing, etc. (E-waste Technologies Africa, n.d.)

The EWT are members of EWASA, the Seda NMB ICT Incubator, The Institute of Waste Management of South Africa, an affiliate of the South Africa E-Waste Alliance (SAEWA).

Local businesses are picking up the slack. What has historically been neglected in terms of enforcement of international law and corporate accountability is now being met with stronger organizing of local initiatives and resources. The potential for a successful e-waste industry is hindered by South Africa's overall lack of understanding surrounding economic benefits of the industry as a whole. Luckily, this trend is changing as companies like Africa E-Waste are stepping in to show that investing in the e-waste industry, being "green and clean," can help businesses gain a competitive advantage. This SME, located in Johannesburg, prides itself on its expertise, adherence to legislation (both national and international), alliances with partners and suppliers, well-rounded service from dismantling to refurbishing to data destruction, concern for the environment and the sustainability of the earth, and its profit maximization on e-scrap.

In contrast to Egypt and Nigeria, South Africa presents a compelling polarity. According to Infrastructure News out of Johannesburg, South Africa, the "majority of 
South Africa's e-waste is being exported" (Naidoo, 2017). The "[South African] waste sector generates around 25 jobs per 1,000 tons of handled e-waste" (Naidoo, 2017). Key findings from a Waste Management Symposium found that "over 100 formally registered companies operate across the WEEE recycling value chain (from collection to processing) in South Africa" (Salhofer, Kopacek, \& Gericke, 2017, p. 8). The potential job market is inviting and deserves much more attention. With innovative technologies emerging this number should continue to grow. 


\section{Chapter 6 Discussion and Conclusion}

\section{Discussion}

All three case studies shed light on the ethical, economical, and social aspects of e-waste opposition. The possible value (economic), the risks of contamination and disease from leftover materials and byproducts of informal recycling (CSR), and the lack of controlled regulation of dumping in marginalized areas (ethical) all coincide. A stabilized business like an SME has the ability to incorporate this tripartite awareness into its framework of e-waste management and even better if SMEs within respective countries could create an emergent network. Local SMEs, are truthfully starting to acknowledge and embrace these three facets of e-waste combattance. A synergistic approach can yield more circular results, rather than linear.

Planned obsolescence is finally being recognized as a problem by the very companies that produce electronics and electrical equipment. These corporations, like Dell, understand the importance of CSR and are attempting to atone for their part in the e-waste pandemic. Yet, the in house SMEs are more concerned with the way CSR is intertwined with e-waste combattance. There should be no difficulty in understanding the economic incentive of this connection for both major international corporations and the variety of SMEs in developing countries. So, the incentives for informal workers to enter the e-waste recycling sector are related to the high profits in commercializing devices or components for reuse and recycling (role of SMEs), combined with the low level of investment needed to participate in this trade. Stronger CSR and a more formalized ewaste industry will protect the well-being, health, and rights of scavengers and scrappers, unlike the hazardous nature of informalized methods of recycling and refurbishing. 
It is interesting to note the similarities and differences between Egypt, Nigeria, and South Africa. Representing three of the strongest economies in Africa, the aforementioned nations have undiscovered potential in not only combattance but also development in an e-waste industry. The inevitable truth is that eradicating all of the millions of metric tons of e-waste worldwide would prove an insurmountable task. There are ways to incorporate CSR, ETJ, and sustainable domestic employment to slow its burgeoning spread. Overall Egypt, is arguably the most archaic in its response to the ewaste problem, and needs substantial assistance in combatting e-waste dumping.

What these three case studies reveal is a post factum response to the e-waste problem. The nature of CSR and environmental theories of justice urge corporations to proactively adhere to environmental sustainability and corporate strategic objectives regardless of locale. The e-waste pollution havens that have emerged as a result of lax environmental regulation and government monitoring as well as corporate neglect necessitate a well-structured and integrative approach to combatting e-waste. The world's e-waste will not be eradicated promptly; this is a vital perspective for major businesses like Dell and Samsung to take.

SMEs in countries like Egypt, Nigeria, and South Africa that have e-waste havens are engaging in their own conversation with CSR all the while correcting years of negligence by larger international businesses. There will come a point, as corporate accountability and transparency grows, where it will be impossible for companies that produce obsolete electronics to maintain the standards of CSR without participating in strategic initiatives in nations that have been historically and drastically affected by ewaste dumping. The PHH explains why e-waste dumpsites are emerging and ballooning 
across Africa. MNCs like Nokia, Dell, and HP are finally catching up with a commitment to corporate social responsibility, in part because of the heightened exposure of e-waste as a dirty industry and their products being a substantial part of the problem. When local SMEs do the work that major multinational firms should already be undertaking, the same multinational firms are compelled to respond in order to maintain a positive reputation and to compete with business models that incorporate CSR, EPR, and ETJ.

\section{Strengths and Limitations}

As with all research, there are limits to certain methodologies. This multi subject case study falls into this distinction. The benefits of this investigation are its embedded nature of the business operations of specific companies within each country actively pursuing e-waste strategies. Unfortunately, this study leaves out the importance of experimentation and the information that quantitative methods can glean. The nature of how e-waste is measured also presents a problem for policy driven solutions. We truly don't know the exact amount of e-waste dumped from developed countries like the United States due to nefarious and covert means of disposal. Estimates do give a general picture, and patterns will form over time.

It would have been incredibly beneficial to conduct research on site in all of the markets and villages mentioned throughout the case studies. This would require substantial time and resources but would ultimately allow for firsthand ethnographic data collection. An analysis of the impact of the ICT Park in Lagos, Nigeria will take decades of detailed research to track its shortcomings and successes. Arguably, this business hub 
presents the most fruitful opportunity of the three case studies in this investigation.

Conducting interviews with a larger sample of CEOs and employees of the various businesses mentioned in each case study would allow for the collection of primary data that the current investigation lacks.

\section{Future Research}

This discussion briefly touched upon a bottom to top solution to the e-waste pandemic in Africa. It has proven as a gateway for more in-depth analysis as shown in the three specific case studies. The variables that affect the growth of e-waste worldwide are inherently interconnected. Though this study investigated a few case studies, it provides an opening for additional quantitative research on an under-researched phenomenon. One such interaction looks at the purchasing power in rural and urban communities. Ethiopia presents an interesting case where this type of discussion could be extended. Here,

The use of many types of EEE is mostly restricted to urban centers, as the lack of electricity and purchasing power in rural communities often hampers the prevalence of devices such as TVs, refrigerators and computers. Nevertheless, these rural communities do make use of battery-powered devices such as torchlights and radios. Thus, e-waste generation in Ethiopia reflects the existing rural-urban disparities with small e-waste volumes in rural areas (predominantly waste batteries, radios and torch lights) and a much broader e-waste mix in urban communities. (Baldé et al., 2015, p. 38)

It would also prove fruitful to conduct field research in the domestic sphere. For example, in Mauritius "a small, relatively wealthy island, it was estimated that $9.3 \mathrm{~kg} / \mathrm{inh}$ of ewaste was generated in 2014" (Baldé et al., 2015, p. 38). Additionally, "in 2011...1.5 
$\mathrm{kg} / \mathrm{inh}$ of e-waste was transferred at waste transfer stations mixed with the other wastes. Mauritius does not have a regular separate collection system for e-waste. Due to absence of this, most households store the e-waste in their homes" (Baldé et al., 2015, p. 38). This last statement compels field researchers to conduct surveys of households to determine levels of awareness, what types of accessible recycling services people elect to use, and whether recycling and proper use of obsolete materials is enforced. Investigating the domestic sector is yet another layer in understanding sound e-waste management.

Other academic disciplines, such as sociology and psychology, should look into the reasons why it is difficult for human beings to "object to the planned obsolescence of today's gadgetry, and to the way the big tech companies pressure customers to upgrade" (Achenbach, 2015). As the world continues to globalize, it is imperative to reconcile with the notion that technology permeates the developed and developing world. This phenomenon places continuous pressure on the developing world to integrate itself into the global power hierarchy. In short, "machine intelligence and digital social networks are now embedded in the basic infrastructure of the developed world" (Achenbach, 2015).

As competition intensifies, developing nations need access to this basic infrastructure. For advancement purposes, this means that countries positioned on the lower rung of the global hierarchy are susceptible to fraudulent practices externally and internally. A beneficial strategy would be to find ways to compel strong cooperation between developed and developing nations "in order to make sure that waste legislation and stringent compliance are adopted and enforced" (Baldé et al, 2015, p. 38). 
Although larger generalizations can be made about the e-waste problem worldwide,

Innovative technologies have to take the regional context into account. What could be a highly effective technology/solution in e.g. a Western European (highly industrialized) context can be a completely misguided approach in Africa or Asia (developing, industrializing context) - and vice versa. Implementing a high-tech, capital intensive recycling process will not be suitable in every country or region, and hence cannot be regarded as innovative per se. (Schluep et al., 2009, p. 16)

SMEs present a plausible solution within the African context. These entities have the ability to bridge the gap between workers and government as well as local and international relations. Scavengers, if incorporated into a formal economy of e-waste can lower the unemployment rate and contribute to the overall GDP of a country. This investigation demonstrates that there is a changing narrative surrounding SMEs' indifferent approach to e-waste management.

Most of the research, including my three case studies of Egypt, Nigeria, and South Africa, is conducted in urban areas. Even though access to ICT goods is limited in rural areas, it still exists. A handful of towns in various countries in Africa have use for a certain amount of electronic goods. The salvageable products from successful e-waste refurbishment can be distributed by local metropolitan SMEs to create a symbiotic ewaste industry. The e-waste is recycled, SMEs build their business, and rural villages and smaller towns have access to goods that are often hard to obtain.

\section{Conclusion}

RTB theory and the PHH provide a framework for the rise of the e-waste problem in Africa. The dumping of e-waste in countries like Egypt, Nigeria, and South Africa 
comes as a result of the offloading of goods into areas where regulation is minimally enforced. Large multinational firms are now sponsoring take back initiatives and may reach a point where the e-waste produced is incorporated into their extended corporate plans. My research serves to show that although these three nations are becoming pollution havens there are structures emerging to combat the proliferation of e-waste as a dirty industry. Local SMEs in the case countries take on the tenets of environmental justice and CSR in order to improve working conditions, boost the local economy, and promote business models that strive to salvage as much e-scrap as possible. NGOs are attempting to partner with these SMEs to promote local and national initiatives. SMEs operate strategically in the e-waste context and are forcing multinational firms to no longer address the e-waste problem post-factum.

E-waste presents a harrowing obstacle for this millennium as the global market becomes saturated with the latest technologies. It is the fastest growing international waste current that is invading municipal waste streams. The problem becomes even more exacerbated with the show of international treaties, but lack of enforcement. It is a double-edged sword, fueled by both the exporting and importing states. Nations such as, but not limited to, the United States, Canada, the United Kingdom, need to be held accountable for the heinously large amount of e-waste generated each year. In conjunction with this macro level of the state, micro level companies, recyclers, brokers, and various middle agents need to be exposed for some fraudulent routes they take in within the e-waste trade. Schmidt (2006) states, "used electronics travel murky routes populated by numerous recyclers and brokers working in an unregulated market, devoid of government certification programs" (p. A234). 
Correspondingly, the more techno-trash, the more concerted efforts are needed to stymie the environmental, social, and health hazards it garners. Truthfully, the e-waste sector worldwide provides many unemployable individuals and the poor opportunities for employment, or rather a space to salvage what little can be sold on the market from computers, televisions, refrigerators, generators, cell phones, and the like. As such, we need to "urge governments to provide incentives for informal collectors to create extra jobs in urban centers" (The New Times Rwanda, 2012). This idea, if put in to practice will complement the need for CST and EPR on the part of larger companies, including, but not limited to, Dell, Samsung, and Hewlett Packard.

Where do policy-makers draw the line between eradicating a clear environmental and health problem and what many use as a means of subsistence? In short, "our technology today is so new that we haven't had time to understand how to use it wisely" (Achenbach, 2015). Pope Francis has avowed that “technological development hasn't been matched by development in human values and conscience," (Achenbach, 2015). With technology advancing obsolescence is inevitable. Yet, if we take human values and conscience and couple it with the intentional intellectual pursuit of innovative recycling strategies the e-waste problem can become a lucrative e-waste industry.

It would benefit communities worldwide for there to be a "robust, binding international regime" to aid nations in managing the influx of e-waste, the concurrent consequences, and limited benefits (Terada, 2012). This "robust international regime" coupled with sound, transparent country-level management will slow the e-waste problem for future decades as there is a continuous flow of e-waste from developed to developing countries. This is prime opportunity to limit the externalization of the 
developed world's EEE obsolescence from core nations like the United States, Australia, the countries in the European Union, and Japan. Truthfully, this will not happen without partnership with international corporations and international non-profit organizations and constant attention to CSR.

Without question, positive results will occur when key stakeholders work together to strengthen e-waste initiatives and incorporate notions of CSR. The rapid advance of technology and urbanization exacerbates the e-waste problem, but it also presents one of the most opportunity filled areas of the technological age. Grappling with the e-waste pandemic in Africa presents a compelling case for SME-backed initiatives that would formalize the e-waste industry in the developing world. 


\section{References}

Achenbach, J. (2015). Techno-Skeptics' Objection Growing Louder. The Washington Post. Retrieved December 25, 2015.

Adeola, F. O. (2011). Hazardous Wastes, Industrial Disasters, and Environmental Health Risks: Local and Global Environmental Struggles. New York, NY: Palgrave Macmillan

Africa Institute. (2018). Africa Institute the Organization. http://africainstitute.info/aboutafrica-institute/

Akbostanci, E., Tunç, G. I., \& Türüt-Asik, S. (2007). Pollution haven hypothesis and the role of dirty industries in Turkey's exports. Environment and Development Economics, 12(02), 297-322. doi:10.1017/s1355770x06003512

Akinola, K. (2018). CAPDAN backs Lagos State deal to relocate Computer Village. Technology Times Media Limited. Retrieved from https://technologytimes.ng/capdan-backs-lagos-state-deal-to-relocate-computervillage/

Amachree, M. (2013). Lecture presented at Annual Meeting of the Global E-Waste Management Network in California, San Francisco. Retrieved from https://www.epa.gov/sites/production/files/2014-05/documents/nigeria.pdf

Amorim, C. (2007). Hewlett Packard to aid Africa's e-waste battle. SciDev.Net. Retrieved from https://www.scidev.net/global/icts/news/hewlett-packard-to-aid-africasewaste-battle.html

Amoyaw-Osei Y., Opoku Agyekum O., Pwamang J.A., Mueller E., Fasko R., Schluep M. (2011). Ghana e-Waste country assessment: SBC E-waste Africa Project. Basel Convention. Retrieved from http://www.basel.int/portals/4/basel\%20convention/docs/ewaste/ewasteassessmentghana.pdf

APC News. (2011). E-waste in Egypt: How do you solve a problem you can't quantify?. APC News. Retrieved from https://www.apc.org/en/news/e-waste-egypt-how-doyou-solve-problem-you-can039t

Atlas Obscura. (n.d). Cairo's Garbage City. Atlas Obscura. Retrieved from https://www.atlasobscura.com/places/garbage-city

Azuka, A. I. (2009). The Influx of Used Electronics into Africa: A Perilous Trend. Law, Environment and Development Journal 5(1), 90-106. Retrieved from http://www.lead-journal.org/content/09090.pdf 
Baldé, C.P., Wang, F., Kuehr, R., Huisman, J. (2015). The global e-waste monitor 2014. United Nations University, IAS - SCYCLE, Bonn, Germany. Retrieved from https://i.unu.edu/media/unu.edu/news/52624/UNU-1stGlobal-E-WasteMonitor-2014-small.pdf

Basel Convention. (2017). Profile of Basel Convention Coordinating Centre for Training $\&$ Technology Transfer for the African Region (BCCC-Africa). Retrieved from http://www.basel.org.ng/index.php/about-hot-academy/2017-09-19-15-0358/profile

Basel Convention. (2011). Basel Protocol on Liability and Compensation for Damage Resulting from Transboundary Movements of Hazardous Wastes and their Disposal Basel, 10 December 1999. The Protocol. Retrieved from http://www.basel.int/Countries/StatusofRatifications/TheProtocol/tabid/1345/Defa ult.aspx

Basel Convention. (n.d.). Basel Convention on the Control of Transboundary Movements of Hazardous Wastes and their Disposal Ban Amendment. Retrieved from http://archive.basel.int/pub/baselban.html

BBC World Service. (2018). China Exporting E-Waste to Nigeria. Click-BBC. Retrieved from https://www.bbc.co.uk/sounds/play/w3cswhdd

Bennett, S. (2015). It's 2015: Which States Have E-waste Legislation? Retrieved from http://electronicrecyclers.com/2015/07/it-s-2015-which-states-have-e-wastelegislation

BioRes. (2008). Nigeria Seeks to Limit Imports of 'Junk' Computers. International Centre for Trade and Sustainable Development. Retrieved from http://www.ictsd.org/bridges-news/biores/news/nigeria-seeks-to-limit-imports-ofjunk-computers

BioRes. (2004). Basel Convention Fails to Move on Ban Amendment. International Centre for Trade and Sustainable Development. Retrieved from http://www.ictsd.org/bridges-news/biores/news/basel-convention-fails-to-moveon-ban-amendment

Bu, M., Liu, Z., Wagner, M., \& Yu, X. (2013). Corporate social responsibility and the pollution haven hypothesis: evidence from multinationals' investment decision in China, Asia-Pacific Journal of Accounting \& Economics, 20(1), 85-99. http://doi.org/10.1080/16081625.2013.759175

Campbell, K., \& Christensen, K. (2016). Where Does America's E-waste End Up? GPS Tracker Tells All. PBS. Retrieved from 
https://www.pbs.org/newshour/science/america-e-waste-gps-tracker-tells-allearthfix

Carney, L. (2006). Nigeria fears e-waste 'toxic legacy'. BBC NEWS Africa. Retrieved from http://news.bbc.co.uk/2/hi/africa/6193625.stm

Carroll, A.B. (1999). Corporate social responsibility - evolution of a Definitional construction. Business and Society, 38(3), 268-295. https://doi.org/10.1177/000765039903800303

CEDARE. (2011). Needs Assessment of the E-Waste Sector in Egypt. Centre for Environment for the Arab Region and Europe. Retrieved from http://sustainablerecycling.org/sustainable-recycling/wpcontent/uploads/2015/07/Egypt_CEDARE_NeedsAssmt_2011.pdf

Company News. (2015). "E-waste Collection Drive Concludes in Benin." IT News Africa. Retrieved from http://www.itnewsafrica.com/2015/05/e-waste-collectiondrive-concludes-in-benin/.

Copeland, B.R., \& Taylor M.S. (1994). North-South Trade and the Environment, Quarterly Journal of Economics, 109(3), 755-787. http://dx.doi.org/10.2307/2118421

Cowper-Smith, A., \& Grosois, D.D. (2011). The adoption of corporate social responsibility practices in the airline industry. Journal of Sustainable Tourism. 19(1), 59-77, doi:10.1080/09669582.2010.498918

Daily Mail Reporter. (2011). Who'd be a dustman in Cairo? Revolting pictures of piledup rubbish give Egyptian capital label of Garbage City. Retrieved from http://www.dailymail.co.uk/news/article-2019390/Whod-dustman-CairoRevolting-pictures-piled-rubbish-Egyptian-capital-label-Garbage-City.html

Daily News Egypt. (2016). Switzerland, Egyptian ministry of telecommunications sign E-waste recycling agreement. Retrieved from https://dailynewsegypt.com/2016/03/11/switzerland-egyptian-ministrytelecommunications-sign-e-waste-recycling-agreement/

Desco Electronics Recyclers. (2018).Company Profile. Retrieved from http://ewasterecycling.desco.co.za/index.php/en/about-us/company-profile

Duff, H. (2017). Egyptian Mad Scientists Solution to Electronic Waste. Resource Efficiency and Sustainable Waste Management. Retrieved from https://www.theswitchers.eu/en/switchers/egyptian-mad-scientists-solutionelectronic-waste/ 
Ecroignard, L. (2006). E-waste Legislation in South Africa. Electronics Technical, 47-49. Retrieved from http://www.ee.co.za/wp-content/uploads/legacy/Ewaste\%20legislation.pdf

Egyptian Electronics Recycling Company. (2017). Services. Retrieved from http://www.eerc-group.com/en/services/

El-Din, M. A. (2016). ITG targets recycling 500 tonnes of electronic waste by the end of this year. Retrieved from https://dailynewsegypt.com/2016/06/07/itg-targetsrecycling-500-tonnes-of-electronic-waste-by-the-end-of-this-year/

Eskeland, G., \& Harrison, A. (2003). Moving to Greener Pastures? Multinationals and the Pollution Haven Hypothesis. Journal of Development Economics, 70, 1-23. doi: $10.3386 /$ w8888

E-Terra Technologies. (2018). Top 4 Ways Nigeria can Successfully Tackle E-waste Crisis. Retrieved from http://www.eterra.com.ng/articles/top-4-ways-nigeria-cansuccessfully-tackle-e-waste-crisis/

E-Terra Technologies. (2016). E-Terra Set To Transform E-Waste Management In Nigeria. Retrieved from http://techcabal.com/2016/10/12/e-terra-set-to-transforme-waste-management-in-nigeria/

E-waste Technologies Africa. (n.d.). Corporate Social Responsibility (CSR) Sponsorship. Retrieved from http://www.electronicwaste.co.za/csr_sponsorship.html

Friedman, M. (1970). The Social Responsibility of Business is to Increase its Profits. The New York Times Magazine. 1-6. Retrieved from http://umich.edu/ thecore/doc/Friedman.pdf

Grossman, E. (2006). High Tech Trash: Digital Devices, Hidden Toxics, and Human Health. Washington: Island Press.

Heeks, R., Subramanian, L., \& Jones, C. (2015). Understanding e-Waste Management in Developing Countries: Strategies, Determinants, and Policy Implications in the Indian ICT Sector. Information Technology for Development, 21(4), 653-667, DOI: 10.1080/02681102.2014.886547

International Labour Office (ILO). (2014). Tackling Informality in E-Waste Management: the Potential of Cooperative Enterprises. Geneva. Retrieved from https://www.ilo.org/wcmsp5/groups/public/---ed_dialogue/--sector/documents/publication/wcms_315228.pdf. 
Index Mundi. (2018a). Egypt Imports by Product Chapter in US Dollars - Machinery and Mechanical Appliances; Electrical Equipment; Parts Thereof; Sound Recorders and Reproducers, Television Image and Sound Recorders and Reproducers, and Parts and Accessories of Such Articles - Yearly. Retrieved from http://www.indexmundi.com/trade/imports/?country=eg@ion=16

Index Mundi. (2018b). Nigeria Imports by Product Chapter in US Dollars - Machinery and Mechanical Appliances; Electrical Equipment; Parts Thereof; Sound Recorders and Reproducers, Television Image and Sound Recorders and Reproducers, and Parts and Accessories of Such Articles - Yearly. Retrieved from http://www.indexmundi.com/trade/imports/?country=ng@ion=16

Index Mundi. (2018c).South Africa Imports by Product Chapter in US Dollars Machinery and Mechanical Appliances; Electrical Equipment; Parts Thereof; Sound Recorders and Reproducers, Television Image and Sound Recorders and Reproducers, and Parts and Accessories of Such Articles - Yearly. Retrieved from https://www.indexmundi.com/trade/imports/?country=za@ion=16

Infrastructure News. (2014). SA Companies Start E-Waste Recycling Campaign. Retrieved from http://www.infrastructurene.ws/2014/05/22/sa-companies-start-ewaste-recycling-campaign/

Jiang, W. (2009). Seeking a Strategic Vision for Canada-China Relations. International Journal, 64(4), 891-909. https://doi.org/10.1177/002070200906400403

Kambic, R. (2016, May 27). Local municipalities urge residents to recycle electronics before funding dries up. Retrieved from http://www.chicagotribune.com/suburbs/vernon-hills/news/ct-mun-electronicsrecycling-tl-0602-20160527-story.html

Malakata, M. (2015). "West Africa Turns into Dumping Ground for E-Waste." PC World. Retrieved from https://www.pcworld.com/article/2878492/west-africaturns-into-dumping-ground-for-ewaste.html

Manhart, A., Osibanjo, O., Aderinto, A., \& Prakash, S. (2011, June). Informal e-waste management in Lagos, Nigeria - socio-economic impacts and feasibility of international recycling co-operations [Scholarly project]. Retrieved from http://www.basel.int/Portals/4/Basel Convention/docs/e-waste/Ewaste_Africa_Project_Nigeria.pdf

Mascarenhas O., D’Souza, D., \& George, S. (2016). Ethics of E-waste Management: An Input-Process-Output Analytic Approach. Management and Labour Studies, 41(1), 1-18. https://doi.org/10.1177/0258042X16649467 
Metcalfe, S. (2011). Time to stop our electronic waste being dumped on the developing world. The Guardian. Retrieved from http://www.theguardian.com/sustainablebusiness/electronic-waste-developing-world

Mhlanga, T. (2018). South Africans Are Drowning in E-waste. Retrieved from https://mg.co.za/article/2018-03-16-00-south-africans-are-drowning-in-e-waste

Moyo, A. (2017). S.A. loses E-waste Opportunity to Foreign Countries. ITWeb. Retrieved from http://www.itweb.co.za/content/R80KdWMDJydvbznQ

Naidoo, R. (2017). "Why SA is losing out on full e-waste recycling potential." Infrastructure News. Retrieved from http://www.infrastructurene.ws/2017/05/04/why-sa-is-losing-out-on-full-e-wasterecycling-potential/

Nnorom, I., \& Osibanjo O. (2008). Overview of Electronic Waste (e-waste) Management Practices and Legislations, And Their Poor Applications in the Developing Countries. Resources, Conservation and Recycling, 52(6), 843-58.

Nokia. (2018). People and Planet Report. Retrieved from https://www.nokia.com/sites/default/files/nokia_people_and_planet_report_2017. pdf

Ogunlade, A. (2009/2010). Can the Bamako Convention Adequately Safeguard Africa's Environment in the Context of Transboundary Movement of Hazardous Wastes? Centre for Energy, Petroleum, Mineral law and Policy Annual Review 14(5), 125. Retrieved from https://uod.app.box.com/s/hvkqcrs40907g2gr0sxr2htytfuyqsmf

Okukpon, I. (2015). Towards the Sustainable Management of Electronic Waste in Nigeria: South Africa as a Model. (Doctoral Dissertation, University of Cape Town). Retrieved from https://open.uct.ac.za/bitstream/handle/11427/16730/thesis_law_2015_okukpon_i rekpitan.pdf;sequence $=1$

Olubunmi, A. (2010). Group Urges N\Assembly to Pass The E-waste Bill. PM News Nigeria. Retrieved from http://www.pmnewsnigeria.com/2010/10/29/groupurges-nassembly-to-pass-the-e-waste-bill/

Olutoyin, B. I. (2017). A legal appraisal of the challenges of management of electronic waste in Nigeria. International Journal of Law, 3(2), 07-18. Retrieved from http://www.lawjournals.org/download/96/3-1-32-361.pdf

Petricca, C. (2017). Ewaste in Lagos, Nigeria. The EJAtlas. Retrieved from https://ejatlas.org/conflict/e-waste 
Quak, E. (2015). The Race to the Bottom Explained. The Broker. Retrieved from http://www.thebrokeronline.eu/Blogs/Inclusive-Economy-Europe/The-race-tothe-bottom-explained

Quiros, M. (Photographer). (2014, April). Manshiyat Nasser Cairo, Egypt [digital image]. Retrieved from http://www.manelquiros.com/thegarbagecity/

Raghupathy, L., Krüger C., Chaturvedi, A., Arora, R., \& Henzler, M. (2010). "E-waste recycling in India: Bridging the Gap Between the Informal and Formal Sector." Retrieved from https://www.iswa.org/uploads/tx_iswaknowledgebase/Krueger.pdf

Recyclobekia. (2017, April 1). Recyclobekia in Alex Bibliotheca [Video File]. Retrieved from. https://www.youtube.com/watch?v=wKgLZ_KccU0

Recyclobekia. (2014, April 6). Recyclobekia at Hayah International Academy. [Video File]. Retrieved from https://www.youtube.com/watch?v=LFdfLBbCDc4

Robinson, B. H. (2009). E-waste: An Assessment of Global Production and Environmental Impacts. Science of the Total Environment 408(2), 183-91. https://doi.org/10.1016/j.scitoxtenv.2009.09.044

Rondinelli, D. A. (2004). Creating a Vision for Environmental Responsibility in Multinational Corporations: Executive Leadership and Organizational Change. Journal of International Business Education. 1, 5-22. Retrieved from http://www.neilsonjournals.com/JIBE/sRondinelli.pdf

Rudra, N. (2008). Globalization and the Race to the Bottom in Developing Countries: Who Really Gets Hurt? Cambridge, UK: Cambridge Univ. Press

Salhofer, S., Kopacek, B., Gericke, M. (2017). Developing a Roadmap for E-waste Management in South Africa. Proceedings Sardinia 2017 / Sixteenth International Waste Management and Landfill Symposium/ 2 - 6 October 2017 S. Margherita di Pula, Cagliari, Italy. 1-10.

Samsung Newsroom. (2014). Samsung South Africa Embarks on E-waste Recycling Program. Retrieved from https://news.samsung.com/global/samsung-south-africaembarks-on-e-waste-recycling-program

Schluep, M. (2010). "E-Waste Management in Developing Countries - With a Focus on Africa." EMPA. ITU Symposium on ICTs and the Environment \& Climate Change Cairo, 2-3 November 2010. Retrieved from https://www.itu.int/dms_pub/itu-t/oth/06/0F/T060F00601700404PDFE.pdf 
Schluep M., Hagelüken, C., Kuehr, R., Magalini, F., Maurer, C., Meskers C., Mueller, E., \& Wang, F. (2009). Sustainable Innovation and Technology Transfer Industrial Sector Studies: Recycling - From E-Waste to Resources, United Nations Environment Program and United Nations University. Retrieved from http://www.unep.org/PDF/PressReleases/E-

Waste_publication_screen_FINALVERSIONsml.pdf.

Schmidt, C. W. (2006). Unfair Trade e-Waste in Africa. Environmental Health

Perspectives, 114(4), A232-A235. Retrieved from

http://www.jstor.org.proxy.lib.pdx.edu/stable/3650919

Secretariat of the Basel Convention on the Control of Transboundary Movements of Hazardous Wastes and Their Disposal. (2014). "Basel Convention: On the Control of Transboundary Movements of Hazardous Wastes and their Disposal." UNEP. Retrieved from http://www.basel.int/Portals/4/Basel\%20Convention/docs/text/BaselConventionT ext-e.pdf

Shabi, A. (n.d.). E-waste Management in Lagos State: Current Situation of E-waste Handling - Regulations and Legislation. [PowerPoint Slides]. Retrieved from http://nigeria.ahk.de/fileadmin/ahk_nigeria/Renewable_Energy/Electronic_Waste/ E-Waste_management_in_Lagos_State_-_current_situation.pdf

Smith, S. (2015). Impact Recyclers: Turning E-waste into Jobs through Social Enterprise, Sarah Smith. Retrieved from http://redf.org/impact-recyclers-turning-e-wastejobs-social-enterprise-sarah-smith/

SpearkInk Company. (2014, January 17). Spear Ink Company. [Video File]. Retrieved from https://www.youtube.com/watch?v=Ri_zoNTEDvw

Sullivan, J. (2014). Trash or Treasure: Global Trade and the Accumulation of E-Waste in Lagos, Nigeria. Africa Today, 61(1), 89-112.

Sustainable Recycling Industries. (2015). Egypt - Sustainable Recycling Industries. Retrieved from http://sustainable-recycling.org/recycling-initiatives/egypt/

Swingler, S. (2014). The ABCs of E-Waste. Retrieved from http://gga.org/stories/editions/aif-19-in-the-balance-development-vs.conservation/the-abcs-of-e-waste

Taylor, M. S. (2004). Unbundling the Pollution Haven Hypothesis. Advances in Economic Analysis \& Policy-De Gruyter. 4(2) Article 8, 1-26. Retrieved from https://static1.squarespace.com/static/595683df197aea34b397b2fd/t/59864004a57 
90a7d30cd3fce/1501970437409/Taylor+-

+Unbundling+the+Pollution+Haven+Hypothesis.pdf

Terada, C. (2012). Recycling Electronic Wastes in Nigeria: Putting Environmental and Human Rights at Risk. Northwestern Journal of International Human Rights, 10(3), 154-172. Retrieved from

https://scholarlycommons.law.northwestern.edu/cgi/viewcontent.cgi? article=1129 \&context=njihr

Tewfik, N., \& Shakra, H. (2013). E-waste collection and Treatment-Egypt. Retrieved from http://www.sweep-net.org/e-waste-collection-and

The Initiates PLC. (2018). E-Waste Processing Services. Retrieved from http://initiatesgroup.com/e-waste-recycling-electronic-waste-used-computer-itwaste-in-nigeria-end-of-life-devices-laptops-recycling-recycling-in-nigeria-wastepick-up-process-electronic-waste-management-services-data/

The New Times Rwanda. (2012). Firms explore E-waste recycling business in Africa. The New Times Rwanda. Retrieved from http://www.newtimes.co.rw/section/article/2012-03-19/101631/

The Recycler. (2015). Spearink discusses e-waste and business. Retrieved from https://www.therecycler.com/posts/spearink-discusses-e-waste-and-business/

The World Bank Group. (2016). GINI index (World Bank estimate). Retrieved from http://data.worldbank.org/indicator/SI.POV.GINI

Tong, X., \& Wang, J. (2004). Transnational Flows of E-Waste and Spatial Patterns of Recycling in China. Eurasian Geography and Economics, 45(8), 589-602. https://doi.org/10.2747/1538-7216.45.8.608

United Nations Industrial Development Organization (UNIDO). (2017). What is CSR? Retrieved from http://www.unido.org/csr/o72054.html

United Nations Environment Program and Swedish International Development Agency. (n.d). Introduction to Basel Convention-Session 7. [PowerPoint slides]. Retrieved from http://www.unep.fr/shared/publications/cdrom/DTIx0899xPA/session07_Basel_C onvention.ppt

Vos, S. (2012). Electronic Waste Disposal. Retrieved from http://sites.nicholas.duke.edu/loribennear/2012/11/15/electronic-waste-disposal/

Waste Management (n.d). Responsible E-Waste Management. Retrieved from https://www.wm.com/sustainability- 
services/documents/insights/Responsible\%20E-

Waste\%20Management\%20Insight.pdf

Watson, G. (2014). Practical Guidebooks for South African E-Waste Businesses. News 2014. Retrieved from https://www.giz.de/expertise/html/11036.html

Widmer, R., Oswald-Krapf, H., Sinha-Khetriwal, D., Schnellmann, M., \& Böni, H. (2005). Global Perspectives on E-waste. Environmental Impact Assessment Review, 25(5), 436-458. https://doi.org/10.1016/j.eiar.2005.04.001

Wilkin, J. (2013). E-Waste: Where Do Obsolete Technologies Go to Die? Retrieved from https://tulaneict4d.wordpress.com/2012/11/01/6082/

Williams, A. (2009). EWASTE SOUTH AFRICA [Video File]. Retrieved from https://www.youtube.com/watch?v=IXYq0N4kv7Q

Williamson, R. (2015). Printing Money: Spear Ink's E-waste Ambitions. Retrieved from https://www.wamda.com/memakersge/2015/07/printing-money-spear-inks-ewaste-ambitions

World Resources Forum. (2016). Switzerland Signs Agreement with Egypt to Support Ewaste Recycling. World Resources Forum. Retrieved from https://www.wrforum.org/projects/sri/switzerland-agreement-egypt-e-wasterecycling/

World Resources Forum. (2015). Ghana and Egypt E-waste Programs Kicked off This Month. World Resources Forum. Retrieved from http://www.wrforum.org/events/wrf-events/ghana_egypt_e-waste_sri/ 


\section{Appendix}

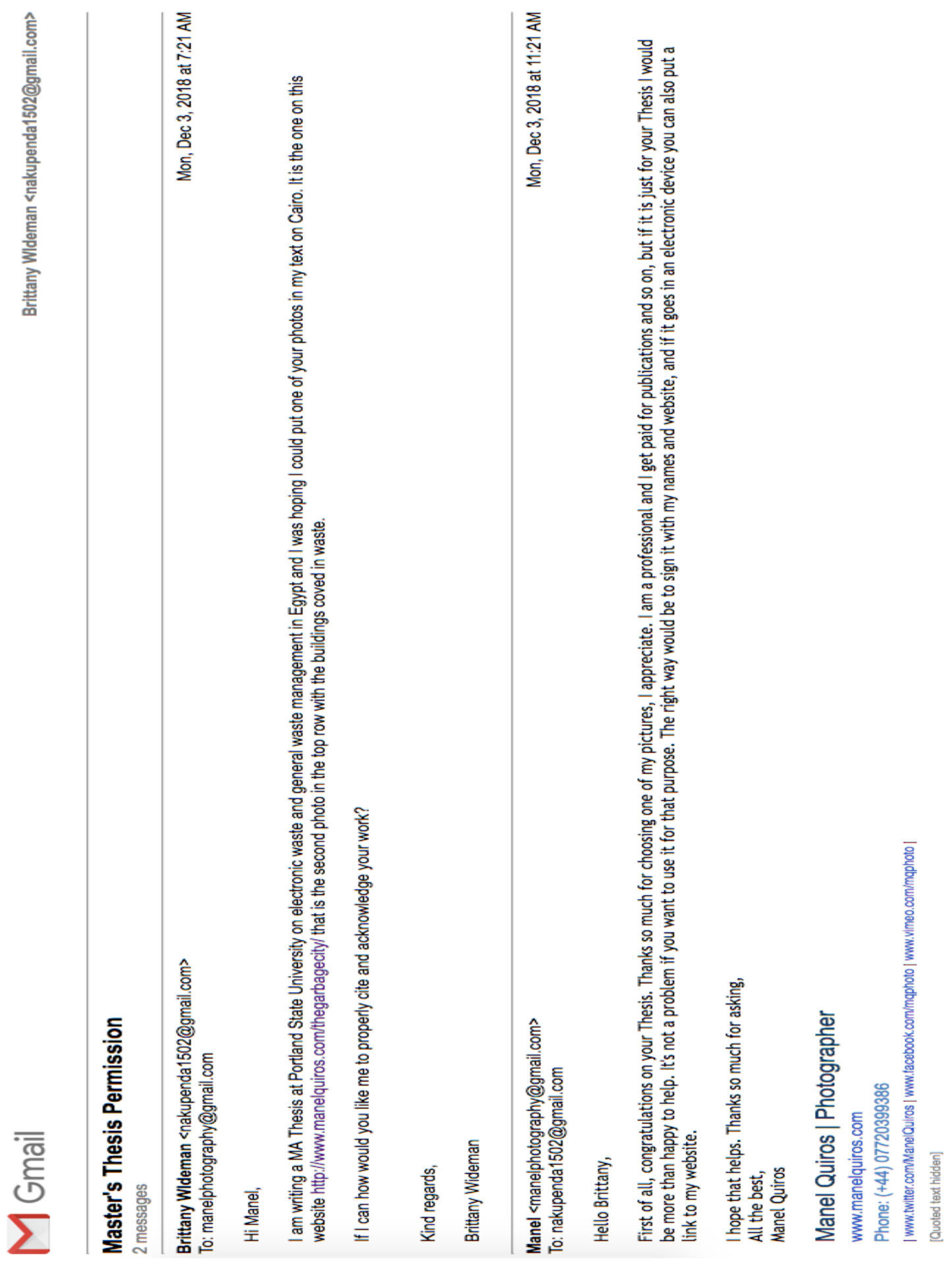

